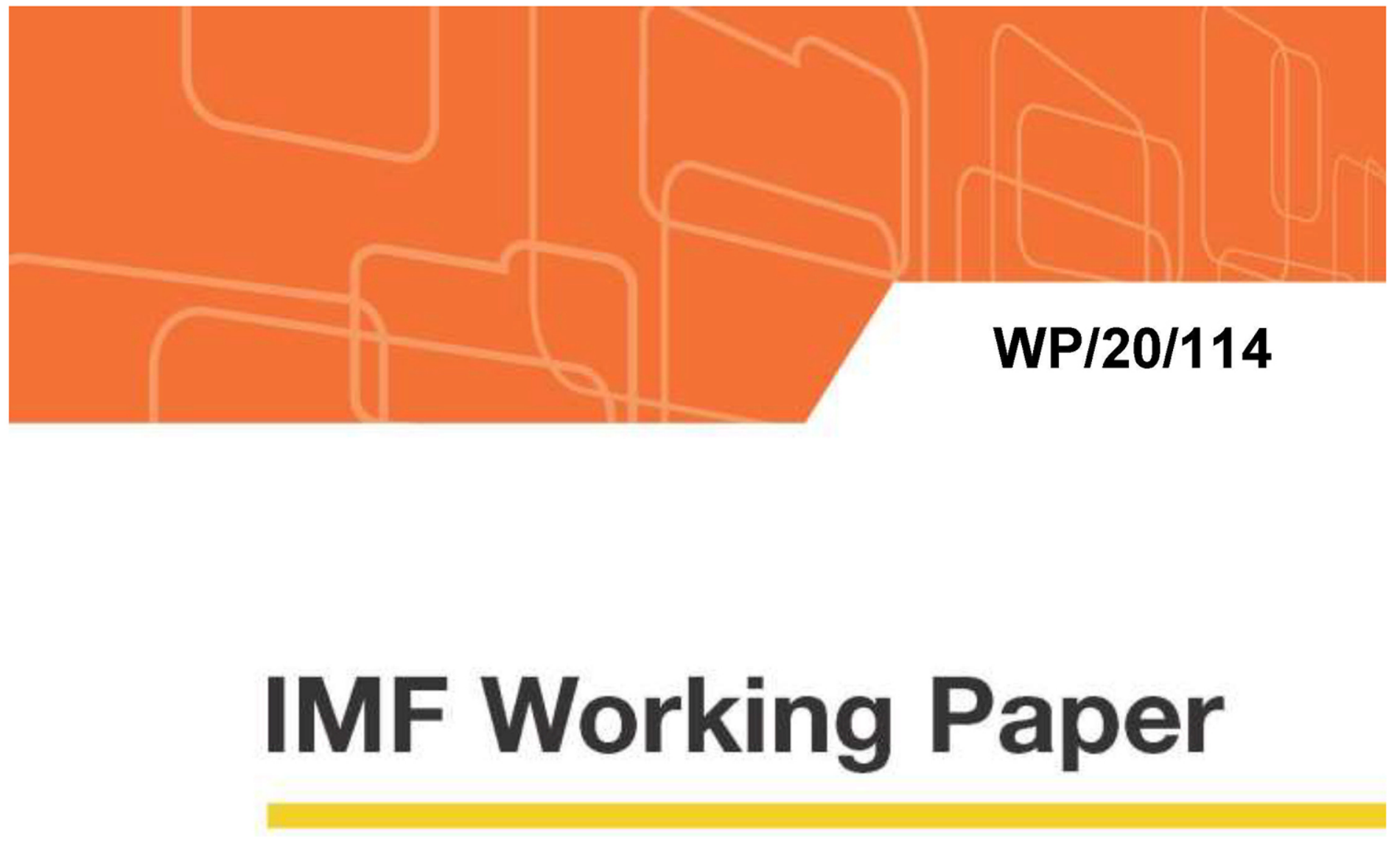

\title{
A TIP Against the COVID-19 Pandemic
}

\author{
by Reda Cherif and Fuad Hasanov
}

IMF Working Papers describe research in progress by the author(s) and are published to elicit comments and to encourage debate. The views expressed in IMF Working Papers are those of the author(s) and do not necessarily represent the views of the IMF, its Executive Board, or IMF management. 


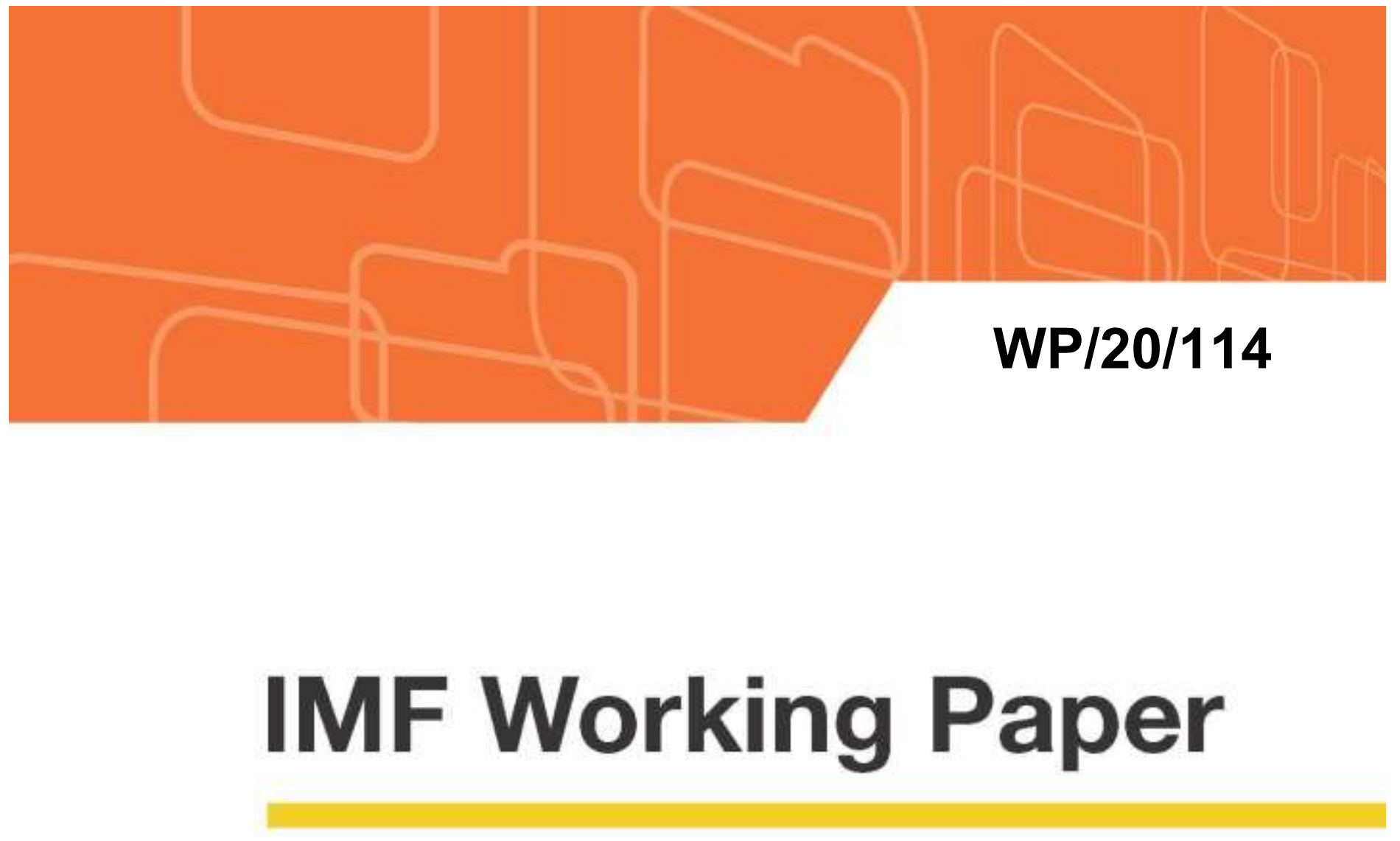

\title{
A TIP Against the COVID-19 Pandemic
}

\author{
by Reda Cherif and Fuad Hasanov
}

IMF Working Papers describe research in progress by the author(s) and are published to elicit comments and to encourage debate. The views expressed in IMF Working Papers are those of the author(s) and do not necessarily represent the views of the IMF, its Executive Board, or IMF management.

$$
\text { I N T E R N A T I O N A L M O N E T A R Y F U N D }
$$




\title{
IMF Working Paper
}

Institute for Capacity Development

\section{A TIP Against the COVID-19 Pandemic}

\section{Prepared by Reda Cherif and Fuad Hasanov ${ }^{1}$}

Authorized for distribution by Rahul Anand

July 2020

\section{IMF Working Papers describe research in progress by the author(s) and are published to elicit comments and to encourage debate. The views expressed in IMF Working Papers are those of the author(s) and do not necessarily represent the views of the IMF, its Executive Board, or IMF management.}

\begin{abstract}
A universal testing and isolation policy is the most viable way to vanquish a pandemic. Its implementation requires: (i) an epidemiological rather than clinical approach to testing, sacrificing accuracy for scalability, convenience and speed; and (ii) state intervention to ramp up production, similar to True Industrial Policy (TIP), on a global level to achieve a scale and speed the market alone would fail to provide. We sketch a strategy to tackle market failures and implement smart testing, especially in densely populated areas. The estimated cost of testing is dwarfed by its return, mitigating the economic fallout of the pandemic.
\end{abstract}

JEL Classification Numbers: O25, E1, I1

Keywords: Industrial policy; growth; manufacturing; epidemic; COVID-19; coronavirus; containment policy; SIR model

Authors’ E-Mail Addresses: acherif@imf.org; fhasanov@imf.org

\footnotetext{
${ }^{1}$ We are grateful to Ralph Chami and Alfred Kammer for valuable suggestions and discussions. We would also like to thank Turki Abalala, Ryadh Alkhareif, Gerard Almekinders, Karim Barhoumi, Fernando Delgado, Murray Green, Samuel Hurtado, Phakawa Jeasakul, Emily Jones, Amine Mati, Maher Mouminah, Marco Pinon, Adam Ritchie, Tahsin Saadi Sedik, Moez Souissi, Sacha Stelzer-Braid, Evan Tanner, Yunhui Zhao, Jing Zhou, and IMF seminar participants for helpful comments. We are grateful to Claudia Cohen and Talia Zulueta for formatting the paper. All errors are our own.
} 


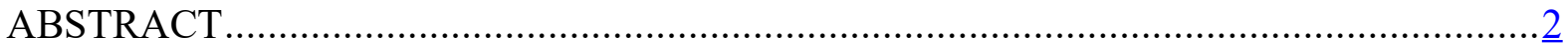

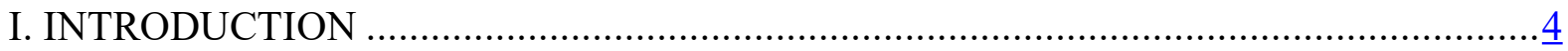

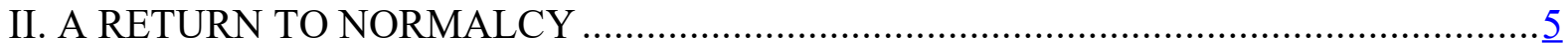

III. TESTING AND ISOLATION POLICY ............................................................. $\underline{8}$

A. Flattening the Curve ................................................................................ $\underline{8}$

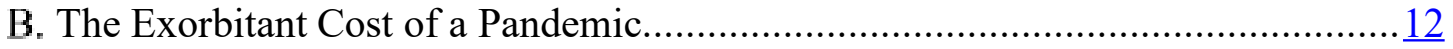

C. Testing and Isolation Policy: Squashing the Curve ..................................... 14

D. Squashing the Curve, or Exit Strategy in a Densely Populated Area ...................16

E. Smart Testing Strategies ................................................................. 21

F. An Epidemiological Approach to Testing ............................................ 25

IV. MARKET FAILURES IN TESTING TIMES................................................... 28

A. From the Invisible Hand of the Market to the Leading Hand of the State ............ 28

B. Sketching a Strategy .............................................................................. $\frac{31}{33}$

C. Learning from the WWII's Production Ramp Up ..................................... $\frac{33}{36}$

D. Why Most Developing Countries Should Follow TIP Now …......................... $\underline{36}$

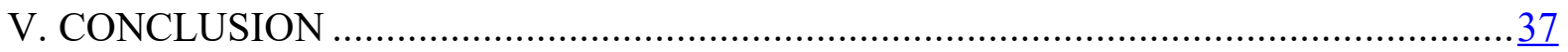

\section{FIGURES}

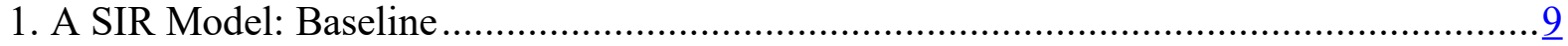

2. Intervention: Social Distancing (10-day Lag and Immediate)................................. 10

3. The Second Wave of the Epidemic ........................................................................... 11

4. U.S. Real GDP and Pre-2007 Trend $(2010$ \$)........................................................ 13

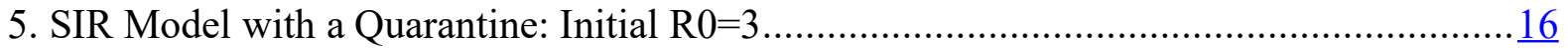

6. Phase Two with Mobility: Number of Infected (Initial R0=3) ................................19

7. Travel Restrictions: Number of Infected (Initial R0=3) ..................................... 20

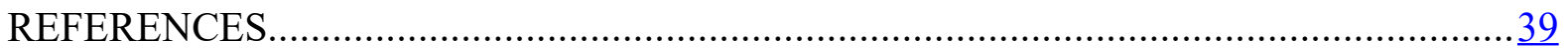




\section{INTRODUCTION}

The world is in the race against time to vanquish COVID-19, a disease resulting from the novel coronavirus that was first reported in Wuhan, China, and spread rapidly across the world in the early months of 2020. After millions of cases and hundreds of thousands of deceased (Johns Hopkins University 2020), extraordinary strains on health care and medical personnel, national lockdowns, and economic fallouts unseen since the Great Depression of the 1930s, the world has yet to see a viable global strategy. The pandemic requires a global solution since a "whack-a-mole" strategy may leave many parts of the globe isolated and vulnerable with a risk of re-importing the virus.

We argue that the most viable way to squash the pandemic is a universal testing and isolation policy. Using a Susceptible, Infected, and Recovered (SIR) model, we argue that a continuous universal testing and isolation of the infected, at a rate of about 5-10 percent of the population per day, would lead to a rapid reopening of the economy and prevent a second wave of the epidemic. We show that in densely populated areas this policy would consider the patterns of movement, especially commuting. Measures to discourage mobility to the hubs or urban centers would increase the efficiency of testing while largely preserving economic activity. "Smart" testing strategies such as group (pooling individual samples for testing) and periodic testing as opposed to random testing (e.g., using blocks of population on a geographic grid) are needed; otherwise the daily testing rate required would increase to $20-30$ percent of the population.

To achieve universal testing, we argue that policymakers must change their perspective to: (i) adopt an epidemiological rather than clinical approach to testing, sacrificing accuracy (sensitivity and specificity) for scalability, convenience, and speed; and (ii) implement an industrial policy to tackle market failures to ramp up production quickly. The aim of an epidemiological approach to testing is to regularly identify (and isolate) enough infected individuals rather than provide a precise clinical diagnosis. Rapid serological tests for antibodies (IgM) or antigens, which are similar to pregnancy tests, and point-of-care rapid molecular tests could be good candidates to reach a large share of the population. Adding to the mix symptom-based tests to identify the infected, could reduce the number of tests needed substantially, below 5 percent of the population a day. This type of "tests" (including fever measurement) could be implemented immediately albeit at the cost of isolating many false positives but still a fraction of the cost of a lockdown.

While the supply of test kits is ramped up in the transition phase, this approach could be complemented with other optimizing strategies. Prioritizing potential infection clusters or hubs (e.g., hospitals, senior housing, prisons, grocery stores, schools, public gatherings, etc.) could reduce the virus spread substantially. Evidence suggests that about 20 percent of the infected generates about 80 percent of the transmission due to superspreader events (Adam and Cowling 2020). Light non-pharmaceutical intervention (NPI) measures such as maintaining distance in public and mask wearing could further reduce transmission rates.

The market failures precluding an unprecedented increase in production of tests in a short period of time at the global level would require a state intervention strategy along the lines of 
a True Industrial Policy (TIP) (Cherif and Hasanov 2019). ${ }^{2}$ We sketch a strategy of such an intervention - industrial policy for the pandemic - which could be implemented successfully in developing countries as well. The intervention amounts to solving the market failures effectively and fast. TIP's key principles such as creating capabilities in sophisticated products with competition (domestic and international) and accountability for the support received are even more important in developing countries. Because the ramp up of production must be done fast, organization and coordination of resources would be key to success. Public and private resources need be directed to the production of the necessary medical products for testing along the whole value chain; knowledge needs to be shared and risks assumed by the state; and manufacturing facilities need to be redesigned or built from scratch quickly. Resources need to be pooled to achieve economies of scale and various international institutions could help developing countries achieve this objective.

The production mobilization is also an opportunity for the developing countries that undertake it to jumpstart or expand manufacturing, and even more important, to get ready for the future vaccine production. This strategy would mitigate not only short-term economic fallout due to lockdowns and a decline in tourism and commodity revenues, but also pave the way for longterm growth with the creation of manufacturing capabilities and facilities.

\section{A RETURn TO NORMALCY}

Waiting for the development of a successful cure or a vaccine to defeat the pandemic could take time the world does not have. Unparalleled in history for speed and global sharing of scientific knowledge, clinical trials of potential vaccines and drugs started in mid-March 2020 after the genetic sequence of the virus SARS-CoV-2 was published by Chinese researchers on January 11, 2020. However, even with the ongoing global collaboration, there is huge uncertainty about the time it would to take - months or years - to find a vaccine or a cure. Evidence that the virus has mutated rapidly adds even more uncertainty and increases the possibility of reinfections (Korber and others 2020). For developing countries lacking production capabilities, the discovery of a cure or a vaccine is only the first step in a potentially long and difficult process to secure the quantities they need (Okonjo-Iweala 2020).

In the face of the pandemic most countries have resorted to national lockdowns to "flatten the curve," or spread out the infection over time, and save lives. Despite the advance of science, the world has essentially resorted to the same measures of the 1918 Great Influenza pandemic. Krugman (2020) argues that although the lockdowns entail a huge cost, GDP and money are not the end but means to an end of improving the quality of life, the main component of which is not dying. Moreover, some evidence suggests that a full lockdown implemented early enough would have comparable economic effects to the case in which the pandemic were left unchecked (Demirguc-Kunt, Lokshin, and Torre 2020).

\footnotetext{
2 The state intervention has been adopted when it comes to vaccines. For instance, AstraZeneca, the UK's pharmaceutical company, working together with the University of Oxford on the development of a vaccine, has obtained a billion dollars of funding from the U.S. drug development agency (BARDA) and secured manufacturing facilities to produce a billion doses of vaccine per year to be operational in 3 months (The Economist 2020a).
} 
Although necessary if the initial phase of the infection is missed, the lockdown strategy can only be temporary and cannot prevent a resurgence. A perfect lockdown to eradicate the disease is next to impossible as essential workers in food and medical production, delivery, and other industries are at work. In the U.S. for example, only 37 percent of jobs can be done at home with much lower share in developing countries (Dingel and Neiman 2020). The resulting economic fallout is exorbitant, especially in developing countries, and cannot last beyond a few months without unintended and dramatic consequences. Lifting restrictions and lockdowns, even gradually, may not prevent the advent of a second wave of the disease and further shutdowns later experienced during the 1918 Great Influenza pandemic.

As lockdowns were being implemented, the debate about saving lives or saving jobs, or contagion vs. starvation in developing countries, ensued. Rather, the policy debate should be about expanding the frontier of how much economic activity could be pursued while keeping the epidemic in check (Budish 2020). What is needed is to assess the viability of policies regarding speed in reopening the economy while keeping minimal restrictions, efficiency in keeping the epidemic in check in different contexts (advanced vs. emerging and low-income countries), and their cost. A return to normalcy, that is keeping minimal restrictions on most economic activities, is key to viability. In this framework, policies solely based on nonpharmaceutical interventions (e.g. full or age- and geography-dependent lockdowns, social distancing rules, mask-wearing, temperature checking, and contact tracing) would not be viable as they would at best slow down the epidemic while not helping reopen economies fully and safely. Many of these measures such as strict social distancing or contact tracing would be difficult to implement in developing countries or past a certain stage of the epidemic.

As the debate has focused on applying various social distancing measures to "flatten the curve," countries, regions, or firms that have used large-scale testing have slowed the epidemic substantially. At the onset, Korea has conducted widespread testing that helped it keep the epidemic spread in check. In Italy, the region of Veneto achieved a much slower progression of the epidemic mostly due to its large-scale testing and isolation, including asymptomatic people, than Lombardy. A stark illustration of the efficacy of this policy comes from the small town of Vo' Euganeo in Veneto, where the virus was wiped out within a fortnight after only two rounds of universal testing and isolation of the infected (Zingales 2020). In Germany, despite the official guidance to test only those with symptoms or in contact with the infected, some companies have been testing their employees periodically (e.g. weekly), allowing normal business operations while keeping employees safe (Storbeck 2020). The city of Wuhan in China has tested its whole population of 7 million people in 12 days to prevent the second wave of the epidemic (Fearnow 2020).

A large proportion of presymptomatic and asymptomatic infections, more than half of all infections (Ferretti and others 2020), point to the need for universal testing while suggesting a much lower effectiveness of symptomatic isolation and contact tracing. This approach contrasts from that of the past coronavirus SARS pandemic in 2003. In the SARS pandemic, infection mostly spread about a week after the infected became symptomatic, and infection control through the isolation of the sick early on worked well (Denworth 2020). However, identifying individuals with symptoms related to COVID-19 could constitute a type of epidemiological "test" that could be used, especially in the transition phase to universal 
testing. In fact, in contrast to the clinical approach and public health directives to test symptomatic individuals, an epidemiological approach largely calls for testing all but symptomatic individuals, which could be screened based on symptoms such as high temperature (e.g., using thermic cameras). Combining this "test" with contact tracing may help identify potentially infected individuals as well. Nonetheless, the presymptomatic/asymptomatic features of this pandemic make contact tracing rather ineffective unless it is done very early in an environment of low prevalence rate, coupled with extremely efficient tracing and fast quarantine rather than active monitoring (Peak and others 2020 and Hellewell and others 2020).

There is a growing chorus of voices arguing that testing is key, and countries need to increase their daily rate of testing in combination with other measures (Romer 2020a and 2020b, Siddarth and Weyl 2020, Baldwin 2020, Berger, Herkenhoff, and Mongey 2020, Brotherhood and others 2020, Eichenbaum, Rebelo, and Trabandt 2020a, Bethune and Korinek 2020, Acemoglu and others 2020, and Piguillem and Shi 2020). However, there is no consensus as to how much testing is needed and to what extent other measures are required although experts do agree on the continuation of social distancing measures and other restrictions in their absence. Our simulation results call for higher random testing rates than Romer (2020b) and Siddarth and Weyl (2020) but a smaller number of periodic tests than Romer (2020b) and broadly similar number of tests as Siddarth and Weyl (2020) to keep the epidemic in check. Testing rates in many countries, including smaller economies, fall far below what these studies call for. By late June 2020, the maximum daily (on a 7-day rolling average) population testing rates have been achieved by Luxembourg (0.9 percent), Bahrain and Iceland ( 0.5 percent), and Denmark and Lithuania (0.25 percent) (Roser et. al. 2020). We contribute to the literature by tackling the feasibility of achieving the testing rates needed. We suggest an alternative epidemiological approach to testing emphasizing scalability, convenience, and speed of tests (including symptom-based "tests") rather than accuracy. Moreover, we offer a sketch of the policies needed to achieve the production of tests needed, especially in an environment of low capabilities as in developing countries.

Although experts agree on its ability to "squash the curve," universal testing has not gained much traction because it has been considered "infeasible." Indeed, the sheer number of tests needed compared to current production in each country and the difficulty of scaling up collecting and processing samples could suggest that this task is impossible (e.g. Kofler and Baylis 2020 and Rose 2020). Huge shortages of ventilators and personal protective equipment across the world, including in many advanced economies, seem to confirm this view (e.g. Azmeh 2020 and Bradley 2020). The perception of "infeasibility" of universal testing stems from the adoption of a clinical approach to testing and "laissez faire" approach to production. The market for tests in the context of a raging pandemic is laden with market failures stemming from uncertainty, capacity constraints, coordination failures, externalities such as a positive externality of massive testing akin to network effects and of resilience rather than efficiency in production decisions, and market power. In addition, the market would not internalize the long-run positive spillover effects of a production increase and would underprovide the socially optimal amount.

The feasibility of a rapid scale up in the production of tests is akin to war mobilization efforts during WWII, when the U.S. and the Soviet Union increased drastically their production of 
military equipment and machinery on an unprecedented scale and in a record amount of time, in some instances building ammunition factories from scratch in 3 months. The potential existential threat of war motivated policymakers to spring into action. Although not trivial, the current task is minuscule in comparison, while the danger of an endemic pandemic is real with huge costs. To put it in perspective, the cost of the monthly ramp up amounts on average to about one to two weeks of global economic losses projected over 2020. This is a miniscule amount and well within the production possibility frontier compared to what was done during WWII, during which total output grew by double digits a year. The number of test kits needed is only a fraction of the number of soft drink cans consumed globally (about a trillion per year). If enough firms pull their resources, combined with substantial public funding, support and coordination, most countries could meet the demand for tests in a matter of few months.

\section{Testing ANd Isolation Policy}

\section{A. Flattening the Curve}

The workhorse model in epidemiological studies, a parsimonious compartmental epidemiological model-Susceptible, Infected, and Recovered (SIR) - shows that infection control is essential to avoid straining the health care system and to save lives. We use this model to illustrate that early and aggressive social distancing measures can only buy some time. With restrictions lifted, the second wave of the epidemic is going to hit. The epidemic is only slowed down by relatively stringent social distancing measures, or "flattening of the curve," but it would eventually infect most of the population. With more extreme measures such as prolonged lockdowns the cost to halt the epidemic is exorbitant. In the absence of a cure or a vaccine, the only sustainable and effective alternative consists in systematic testing to identify the infected and isolate them.

At the beginning of the outbreak, everyone in the population $(N)$ is susceptible $(S)$ since it is a novel virus. Individuals become infectious, joining the group of infected $(I)$, at certain infection rate $(\beta)$. After the infected stage, individuals move to the recovered stage $(\mathrm{R})$ at a recovery rate $(\gamma)$. The sum of individuals in all stages equals the constant population, $N=S+$ $I+R$ (Hill and others 2020).

A simple version of the SIR model takes the following form (with the dot indicating a time derivative):

$$
\begin{aligned}
& \&=-\frac{\beta S I}{N} \\
& \&=\frac{\beta S I}{N}-\gamma I \\
& k=\gamma I
\end{aligned}
$$

The recovered stage could also include death with different recovery and mortality rates. The model can also incorporate various stages of the infection - mild, severe, and critical infection - that can help assess the impact of the epidemic on the hospital system. With several stages of the infection, some individuals after the mild infection move to the severe and critical stages, while others recover. Another version of the model is a SEIR model, which 
includes an Exposed state, before the Infected one, and it can accommodate asymptomatic cases as observed in the current pandemic (Hill and others 2020). We use the simplest version without a loss of generality.

The key parameter in these types of models - the basic reproduction number $\left(R_{0}\right)$-indicates whether the outbreak results in an epidemic. $R_{0}$ is the expected number of secondary cases produced by a single infection before recovery in a completely susceptible population (Jones 2007). In a simple SIR model, it is equal to the ratio of the infection rate to the recovery rate $\left(R_{0}=\beta / \gamma\right){ }^{3}$ This number is important because if it is greater than one (assuming everyone is susceptible in the beginning), the number of the infected grows and afflicts a large part of the population, resulting in an epidemic. However, if $R_{0}$ is less than one, then the number of the infected falls, and eventually the epidemic wanes.

Without non-pharmaceutical interventions (NPIs), an epidemic evolves quickly. Figure 1 shows the path of the susceptible, infected, and the recovered with $R_{0}$ equal about 3 , implying that infections double every 5 days. This $R_{0}$ is consistent with data from Wuhan, China, in January 2020 (Verity and others 2020) although more recent work suggests that $R_{0}$ in Wuhan could have been as high as 5.7 with the number of infections doubling every 3 days (Sanche and others 2020). A faster spread would put more strain on the health system, resulting in higher mortality.

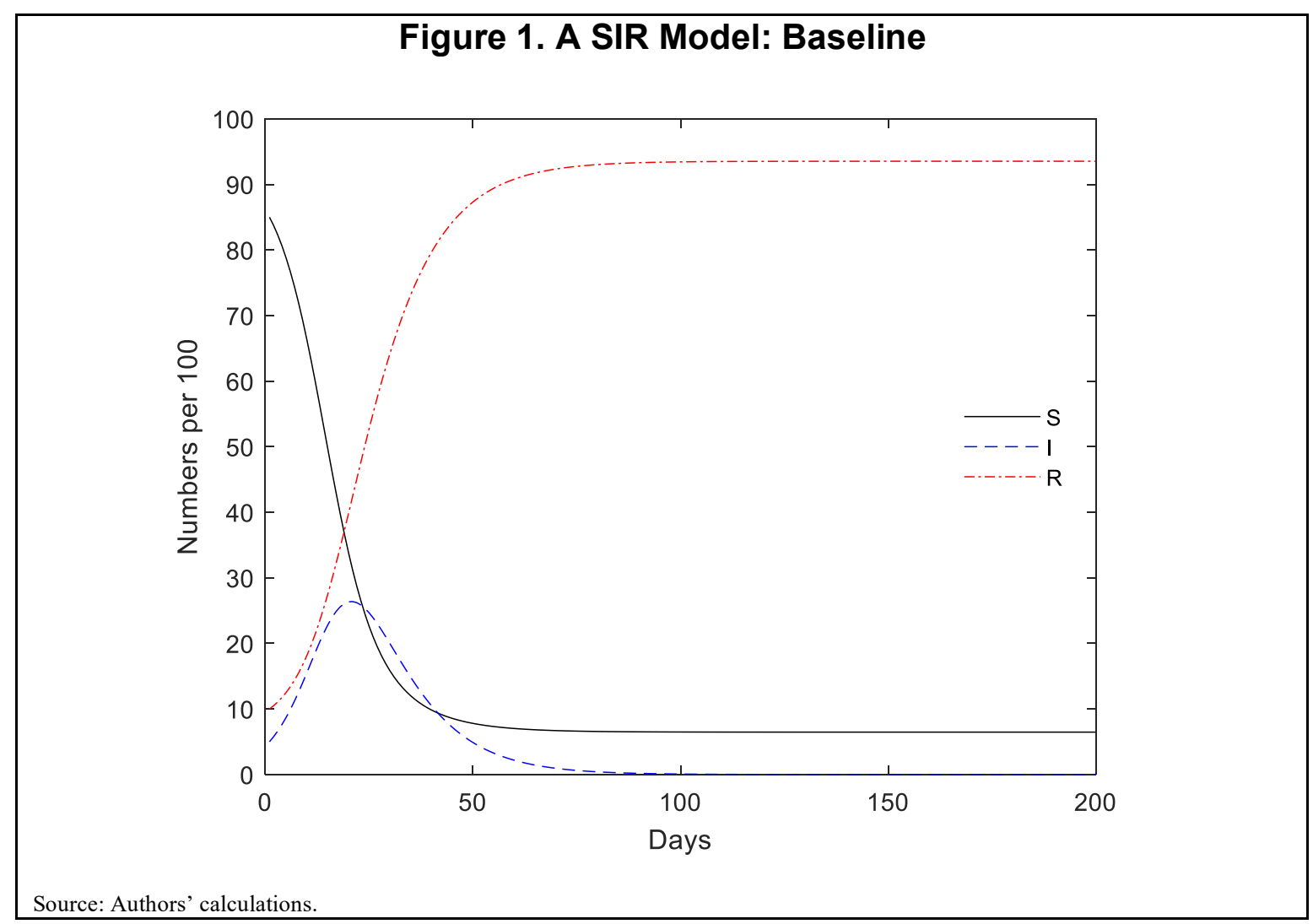

\footnotetext{
${ }^{3}$ Alternatively, since the average number of days between contacts is $T_{c}=1 / \beta$ and the average number of days until recovery is $T_{R}=1 / \gamma$, then $R_{0}$ is $T_{R} / T_{c}$.
} 
The strategy of "flattening the curve" is clearly seen if the infection rate is lowered through interventions such as social distancing. This would help avoid overwhelming the health care system at any point in time by ensuring that the number of severely ill at the peak remains below the hospitals' capacity. In addition, the closer to the peak of the epidemic the intervention starts, the smaller the effect of the intervention is, calling for early interventions. In our SIR model, a social distancing intervention can be illustrated by reducing the transmission rate by 50 percent and bringing down $R_{0}$ from 3 to 1.5 immediately or after 10 days of the onset of the epidemic (Figure 2).

\section{Figure 2. Intervention: Social Distancing (10-day Lag and Immediate)}

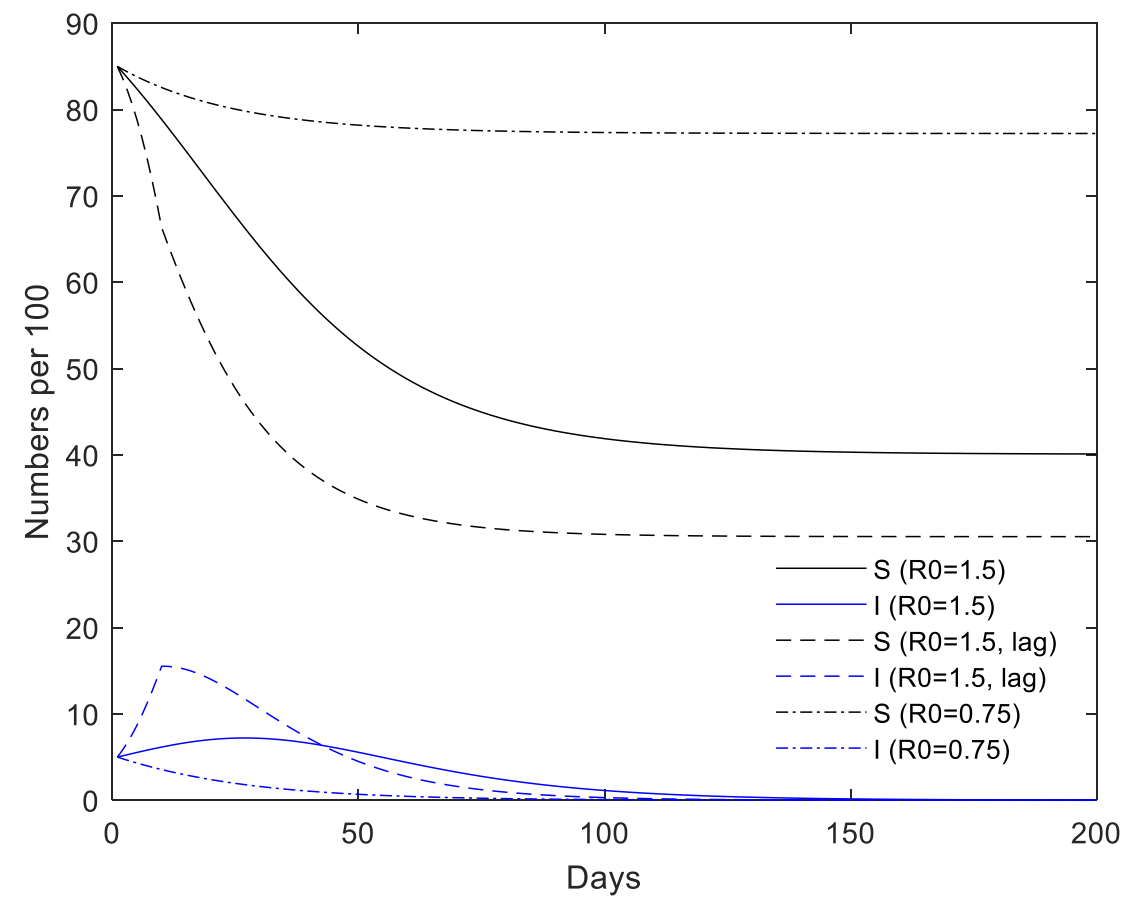

Source: Authors' calculations

While a reduction in $R_{0}$ would always reduce the speed of contagion, if it is not reduced below one, the disease would eventually infect a large majority of the population (Figure 2). The reduction in $R_{0}$ is achieved with relatively strict social distancing measures and yet, with $R_{0}$ of even slightly above one, the epidemic is not eradicated. It lingers for a long time, infecting a large part of the susceptible population, while still requiring the continuation of the intervention. More important, in most developing countries with relatively weak health care systems, simply "flattening the curve" would still overwhelm the hospitals' capacity, resulting in higher mortality.

Instead of "flattening the curve", an alternative strategy consists in "squashing the curve" by imposing stringent measures such as lockdowns and business and school closures. By bringing $R_{0}$ substantially below one, the number of infected would dwindle rapidly while sparing most of the population from the infection. This has been the case in many areas under 
lockdown such as in several Chinese cities and provinces, where $R_{0}$ fell below one (Leung and others 2020). With a 75 percent reduction in the transmission or infection rate, $R_{0}$ falls below one to 0.75 , which would decrease the number of infected rapidly, eventually eradicating the epidemic (Figure 2). However, it takes a long time, a little over 3 months, to bring the number of the infected to about one in a thousand, for example. The large reduction in the infection rate is consistent with extreme measures such as lockdowns. Most developing countries have no choice but to impose these measures as early as possible to contain the outbreak, especially as social distancing measures may not work well in dense urban areas.

\section{Social Distancing or a Lockdown Only Buys Time}

Even if the epidemic is contained while a large part of the population is still uninfected, lifting NPIs such as strict social distancing and lockdown measures would potentially lead to a "second wave" or a resurgence of the epidemic. In our previous example, in which after the lockdown, the epidemic is slowed down and $R_{0}$ is reduced to 0.75 , we assume that 40 days later (at this point the number of infected is about one out of a hundred), the lockdown is lifted and $R_{0}$ goes back to 1.5 - a level with social distancing measures. Leung and others (2020) argue that $R_{0}$ would increase above one in Chinese cities if strict restrictions were to be lifted. Indeed, the epidemic does come back slowly, infecting a large number of people as the susceptible population declines (Figure 3 ). And if social distancing measures are light and $R_{0}$ goes back to its initial level of 3 , then the number of infected increases quickly.

Figure 3. The Second Wave of the Epidemic

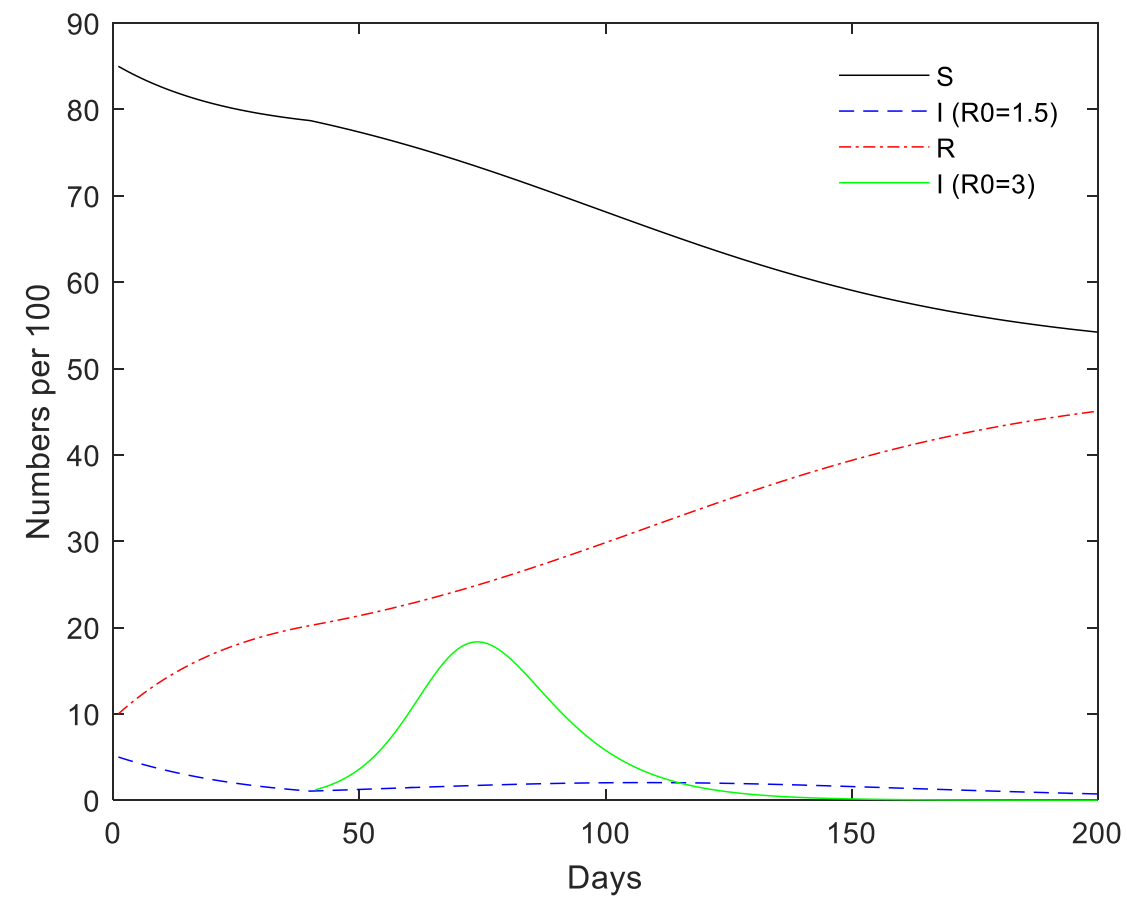

Source: Authors' calculations. 
The empirical evidence from the 1918 Flu Pandemic corroborates the importance of enforcing and maintaining strict interventions to contain the epidemic. When social restrictions were relaxed, many cities in the US witnessed a second and deadly wave of infections (Strochlic and Champine 2020). For instance, St. Louis relaxed restrictions on public gatherings less than two months after it enforced a lockdown and ended up with a resurgence of cases. However, it still suffered a smaller number of deaths than Philadelphia that had implemented restrictions late, about two weeks after the first few reported cases. In terms of NPIs, these cities were not atypical as only a few cities had kept social distancing interventions in place for more than 6 weeks and most interventions were relaxed within 2-8 weeks (Hatchett, Mecher, and Lipsitch 2007). The cities that reduced their peak mortality rates and escaped the second wave introduced early and effective restrictions and then reintroduced them once the transmission started rising again (Bootsma and Ferguson 2007).

Based on past pandemics, Moore and others (2020) argue that in the next couple of years, the COVID-19 pandemic may persist until a vaccine arrives or herd immunity of about 60 percent to 70 percent of population is achieved. The pandemic may manifest itself as waves and valleys or a peak wave in the fall 2020, which may require reinstituting mitigation measures, or a slow burn, which may not need mitigation measures but would still result in continuing fatalities.

\section{B. The Exorbitant Cost of a Pandemic}

Halting the pandemic through strict social distancing and lockdown measures alone would be very costly. It would require prolonged periods of lockdowns and business and school closures, which would not only be costly but also could entail unintended economic and social consequences. The June IMF estimate for the global growth in 2020 due to lockdowns, drop in demand and trade, and supply chain disruptions is -4.9 percent, a drop from 3.3 percent projected in January 2020. This loss in output in 2020 is about $\$ 10$ trillion (in 2011 PPP dollars). In addition, IMF (2020) has estimated about $\$ 8$ trillion (current dollars) of fiscal stimulus is being injected into the world economy, mostly in advanced countries, as economic activity has been rapidly declining. The pandemic toll on the economy, even if measured in temporary losses of output for only one year, is staggering. ${ }^{4}$

Using the U.S. example, which is illustrative of advanced economies, Romer (2020a) and others indicate that the impact of the pandemic could dwarf the deep and long-lasting effect of the 2008 financial crisis. In 2009, the U.S. real output drop compared to its pre-2007 trend was about 12 percent (about \$1.7 trillion). Moreover, by 2019 output had not recovered its pre-2007 trend, resulting in losses of about $\$ 2.8$ trillion per year since 2008 (Figure 4) and these losses could be potentially permanent. The IMF's June World Economic Outlook projects US growth of about -8 percent in 2020, compared to the January projection of 2 percent, resulting in a potential output loss of about $\$ 2.1$ trillion, or about $\$ 175$ billion a

\footnotetext{
${ }^{4}$ In the absence of an alternative, lockdowns may still make sense even from an economic perspective (Eichenbaum, Rebelo, and Trabandt 2020b). Correia, Luck, and Verner (2020) show that in the 1918 Great Influenza Pandemic, the U.S. cities that implemented early and aggressive restrictions, experienced higher manufacturing growth after the pandemic.
} 
month. If the pandemic is more protracted than expected, it would result in further substantial and permanent losses (Cerra, Fatas, and Saxena 2020 and Ma, Rogers, and Zhou 2020).

The economic and human costs of the pandemic and the necessary lockdowns to halt it would be even greater in developing countries. The weakness of the health care systems warrants early and aggressive social distancing measures for many developing countries. Meanwhile, the human cost of such measures could be far greater than in richer economies. In low-income countries, the informal sector, typically in services, constitutes a sizable share of the economy and would be in a complete standstill. These workers are mostly poor and current income consumers with little or no savings, making them and their families vulnerable to even short disruptions. The share of the population that can work from home is much smaller than that in advanced countries, for instance, about 25 percent in Mexico and Turkey (Dingel and Neiman 2020). In addition, the median family is relatively large living in a small space in crowded urban areas, lacking minimum public infrastructure such as access to water or soap. Potential civil strife could ensue if governments lack the resources to deploy support rapidly.

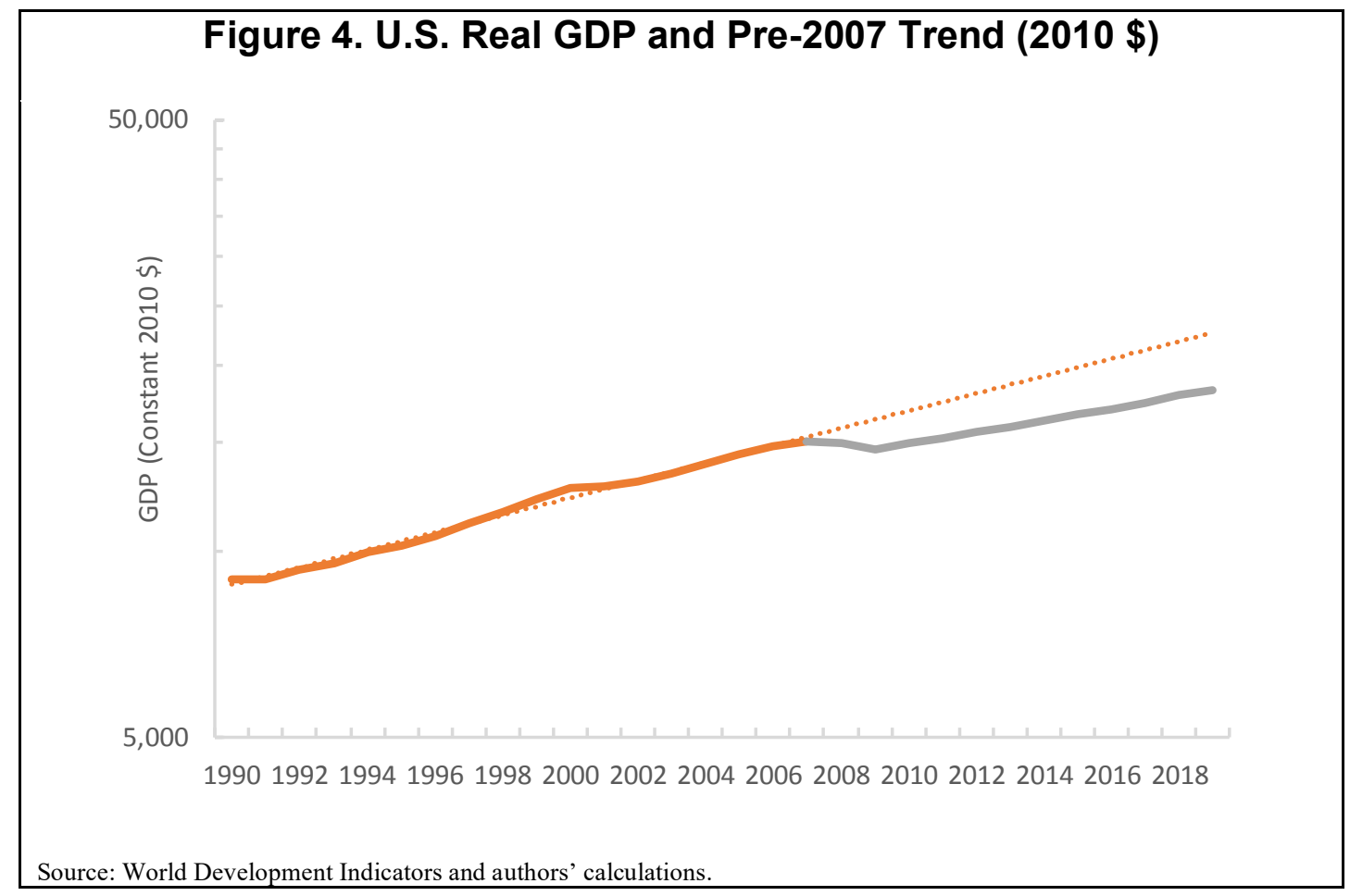

Despite the enormous costs of lockdowns, allowing a pandemic to spread could result in even more colossal costs. The Great Influenza Pandemic of 1918-19 killed on average less than one percent of the population in advanced countries over three successive waves and about 2.1 percent of the global population. In many low-income countries, the devastation was severe. It killed more than 5 percent of the population in Kenya and India, and more than 3 percent in South Africa, Guatemala, and Indonesia (Barro, Ursua, and Weng 2020). Philips (2017) illustrates vividly the destructive and long-lasting effects of the pandemic on the African continent. Brought by demobilized British troops from Europe, it spread rapidly from the main port cities to towns and rural areas reaching every corner of the continent. The disruption was so severe that agricultural activities almost halted, resulting in a diminished harvest and famine or quasi-famine conditions in many areas in 1919. It is also estimated that 
more than 20 million orphaned children were left to fend for themselves in sub-Saharan Africa.

\section{Testing and Isolation Policy: Squashing the Curve}

A cost-effective strategy to "squash the curve" while lifting the lockdown quickly is continuous universal testing and isolation policy. Prolonged lockdowns are not feasible and are very costly. Social distancing measures like small public gatherings and maintaining distance in public reduce the transmission rate but may not bring $R_{0}$ below one. Even if strict social distancing measures are in place and $R_{0}$ hovers slightly above one, the epidemic is slow-moving and continues for a long time, eventually infecting a large number of people. In addition, the measures must stay in place for a long time to keep the epidemic in check. The most feasible alternative is to massively test and isolate the infected if the epidemic is to be squashed quickly and maintain the policy to keep the epidemic under control. More important, in the presence of presymptomatic and asymptomatic cases, this is essentially the fastest method to identify the infected and cut the transmission. In the debate about how to most efficiently restart the economy after a brief lockdown, the quickest and effective way to do so is widespread testing and isolation policy.

Romer (2020a, 2020b) calls for massive and repeated testing. He suggests universal testing of the U.S. population on the order of about 7-7.5 percent per day ( 25 million people/day, or each person every two weeks) quarantining those with positive test results. Romer (2020b) contends that the cost should be less than 1 percent of GDP per year, about $\$ 100$ billion in current dollars, orders of magnitude less than the economic cost so far and even less than the cost of one month of lockdown (\$350-400 billion). Other studies have emphasized a larger proportion of the population, about 20 percent a day, is needed for universal random testing to bring $R_{0}$ below one (Cleevely and others 2020 and Siddarth and Weyl 2020).

We use simulations to underscore the effectiveness of a universal testing and isolation strategy to simultaneously squash the epidemic and re-open the economy relatively quickly. We modify the SIR model to incorporate random testing and isolation of the infected, or quarantine. We assume that at each period a proportion $t^{*}$ of the population is randomly tested, that is $n=t^{*} N$ people are tested. As the proportion of infected in the population is $p$, and assuming a probability of obtaining a false negative is equal to $z$, the expected number of successfully drawn infected individuals in a repeated draw without replacement, would be $n p(1-z) .{ }^{5}$ We assume that the quarantine may not be perfectly implemented with a proportion $e$ escaping the quarantine. It implies that testing would lead to an expected quarantine of (1e) $t^{*} N p(1-z)$, which can be rewritten as $t N p$ where $t$ is the effective share of the population tested (and isolated), or effective testing rate such that, where $q$ is defined as the rate of "leakage" of the tested:

$$
t=(1-e)(1-z) t^{*}=(1-q) t^{*}
$$

\footnotetext{
${ }^{5}$ It is the mean of the hypergeometric distribution of the number of "successes" (or infected) in the sample of size $n$ (number of people tested) with proportion $p$ (of the infected) in the population, assuming no false negatives. In this case, the variance is $n p(1-p)(N-n) /(N-1)$. If the sampling was performed with replacement (i.e., binomial distribution), the expected number of successes would be the same albeit with a greater variance, $n p(1-$ p).
} 
As $Q$ individuals are quarantined, the proportion of the infected becomes $I /(N-Q)$ and the expected number of quarantined equals $t N I /(N-Q)$ (Equation 3). We assume that the leakage $q$ is 25 percent.

$$
\begin{aligned}
& \&=-\frac{\beta S I}{N} \\
& \&=\frac{\beta S I}{N}-\frac{t N I}{N-Q}-\gamma I \\
& \&=\gamma(I+Q) \\
& \mathcal{Q}=\frac{t N I}{N-Q}-\gamma Q
\end{aligned}
$$

We illustrate the evolution of the variables with two scenarios: (i) a systematic isolation and testing policy in the absence of social distancing measures; and (ii) a combination of social distancing and testing and isolation. As in simulations earlier, we assume initially 5 percent of the population is infected and 10 percent is recovered while no one is quarantined.

The simulation with massive random testing and isolation policy and $R_{0}$ of 3 (without much social distancing) can squash the epidemic quickly. With a testing rate of 20 percent of the population a day, the epidemic slows down markedly and the threshold of one infected in a thousand is reached in about 2 months (Figure 5). The share of the susceptible population, however, falls from 85 percent to about 60 percent, implying that still a large number of the population became infected. With a 30 percent testing rate, it takes a little over a month to reach the one in a thousand level of infected with a higher level of the susceptible share of 73 percent and overall smaller number of the infected. This scenario is comparable to the simulation with $R_{0}$ of 0.75 although it takes about two months longer to reach the one in a thousand infected share.

Maintaining social distancing measures while testing reduces substantially the time needed to bring the epidemic under control. If the social distancing is maintained with $R_{0}$ of 1.5 , it takes a little over two weeks with a 30 percent testing rate to bring the infected share to one in a thousand while keeping the susceptible population share at 83 percent. With 20 percent testing rate, it takes about a month (with the susceptible share falling to 80 percent). The results suggest that maintaining social distancing measures would be beneficial as the number of tests needed could be reduced substantially.

To squash the epidemic within a month, however, requires millions of test kits a day for the country like the U.S. If the initial number of infected in the population is relatively small ( 5 percent), the number of tests needed is substantial with $R_{0}$ of 3 to be able to identify a large number of infected relatively fast. Otherwise, the epidemic still affects a large share of the susceptible population. Only with social distancing measures to bring $R_{0}$ to 1.5 could we reduce the number of tests needed while keeping the infected share low. Since the average of the distribution for identifying infected or testing positive is $n p$, we can infer the initial number of tests needed assuming the infected share in the population and the share of population we would like to identify and isolate. In the simulation above, with the initial share of the infected of 5 percent of population and a 15 percent effective rate of identifying 
infected, the initial number of tests a day needed is 66 million (20 percent of population) to squash the epidemic relatively fast. We will discuss in the following sections how this number could be brought down.

Figure 5. SIR Model with a Quarantine: Initial $R_{0}=3$

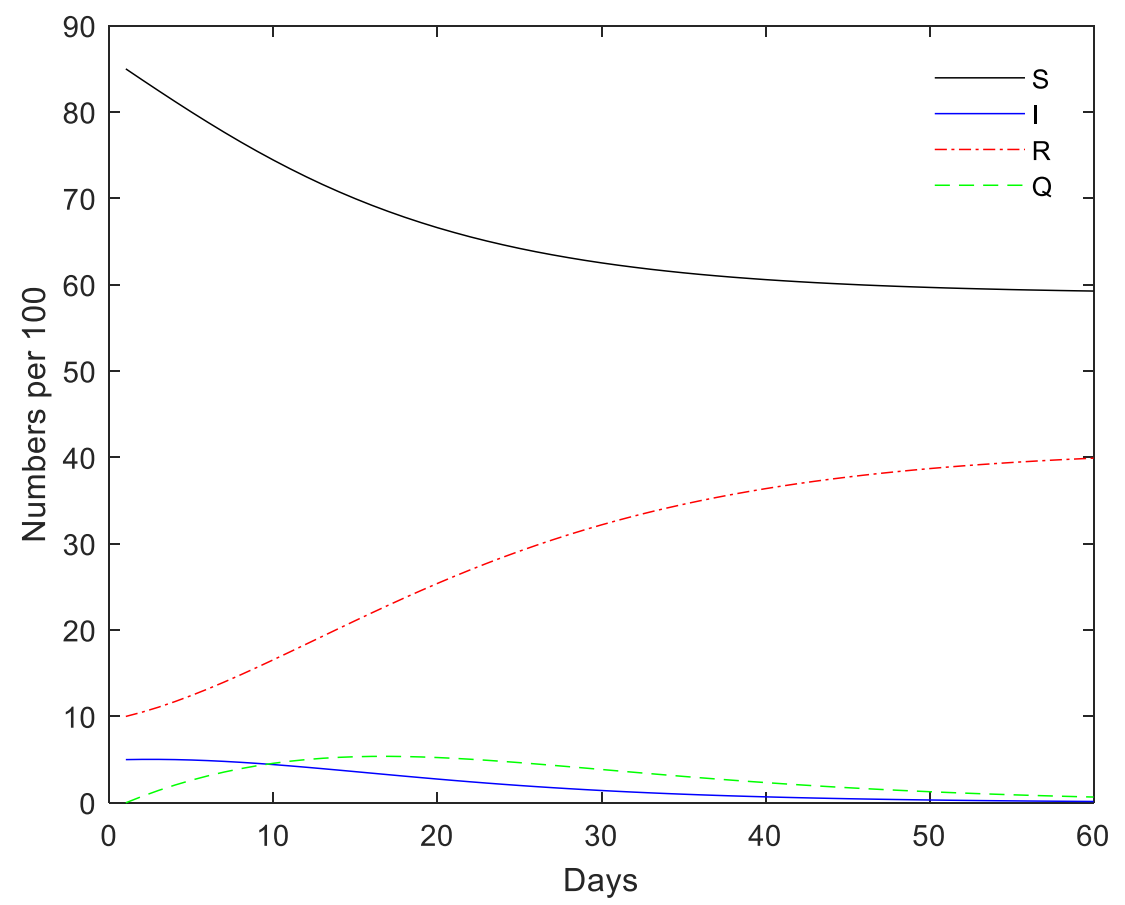

Source: Authors' calculations.

\section{Squashing the Curve, or Exit Strategy in a Densely Populated Area}

Epidemic simulations in the literature suggest that unless strict social and travel restrictions are in place, an epidemic would most likely come back, especially in the presence of a hub. For example, Sanderson (2020), in his simulation in which individuals randomly interact with each other, shows that once NPIs are lifted, the second wave of the epidemic occurs. The spread is more pronounced if the individuals visit a central location (e.g., grocery store, school, etc.) or an urban center. Interestingly, the simulation shows that even with relatively strict social distancing and travel restrictions (90 percent of the population having less contact with each other) and thus lower transmission rate, the epidemic still spreads and infects close to a half of the population, but at a very slow rate. As some individuals slip through the net, the reproduction number $\left(R_{t}\right)$ keeps increasing back to close or above one, and the spread is sustained. The importance of hubs is also corroborated by another study by Dr. Glass, a senior scientist at Sandia National Laboratories in the U.S., and his daughter, showing that the closure of schools in a hypothetical town of 10,000 has reduced the infection by a factor of 10 , from half of the population to about 500 (Lipton and Steinhauer 2020).

Movement of people through a central location becomes critical if one thinks of densely populated cities as patchwork of highly interconnected and traveled across areas. Taking into 
account these patterns in an SIR model with testing and isolation and allowing for mobility and a central hub offers clues as to how to optimize the number of tests needed.

We assume than an area is divided into several similar grids and each grid follows the SIR model with mobility across grids. The central information needed is the Origin-Destination (OD) matrix $C$ (square matrix of size $\mathrm{K}+1$ ), which represents the periodic (daily in our case) movement of individuals across the borders of the grid. This set-up would apply within a city, a region, a country, or cross-country. The element $c(i, j)$ represents the daily number of individuals living in area $i$ traveling to area $j ; x_{j}$ and $s_{i}$ represent the prevalence of the infection (infection rate) in area $j$ and the prevalence of susceptible population (the share of population) in area $i$. By construction, diagonal terms represent the number of individuals that do not move; the sum of terms across columns in a row $i$ is equal to the population of the grid (assumed to be equal across grids); and the sum across rows of a column represents the total number of individuals commuting to region $i$ (including those who do not commute). Potential restrictions on movement across the grid are represented by the elements of the matrix $\alpha_{i, j}$, which lie in $[0,1]$ with diagonal terms equal to one.

$$
\begin{gathered}
\dot{S}_{l}=-\frac{\beta S_{i} I_{i}}{N}-\frac{w \beta S_{i}}{N+\sum_{j \neq i} \alpha_{j, i} c(j, i)-\sum_{j \neq i} \alpha_{i, j} c(i, j)} \sum_{j \neq i} \alpha_{j, i} c(j, i) x_{j}-\frac{w \beta S_{i}}{N} \sum_{j \neq i} \alpha_{i, j} c(i, j) x_{j}^{*} s_{i} \\
\dot{I}_{l}=\frac{\beta S_{i} I_{i}}{N}-\gamma I_{i}-\frac{t N I_{i}}{\left(N-Q_{i}\right)}+\frac{w \beta S_{i}}{\frac{w \beta S_{i}}{N} \sum_{j \neq i} \alpha_{i, j} c(i, j) x_{j}^{*} s_{i}} \sum_{j \neq i} \alpha_{j, i} c(j, i) x_{j}+ \\
\dot{R}_{l}=\gamma I_{i}+\gamma Q_{i} \\
\dot{Q}_{\iota}=\frac{t N I_{i}}{N-Q_{i}}-\gamma Q_{i} \\
x_{j}^{*}=\frac{\sum_{k} \alpha_{k, j} c(k, j) x_{k}}{N+\sum_{k \neq j} \alpha_{k, j} c(k, j)-\sum_{k \neq j} \alpha_{j, k} c(j, k)}
\end{gathered}
$$

We modify the model to allow individuals visiting another grid to potentially infect it and for susceptible individuals returning to their initial grid to import the infection. We also assume that all commuters return to their initial starting grid. To simplify, we assume that the sequence of possible interactions, and potential infections, is as follows: First, all individuals living in a grid interact (first term in the first equation above); second, a number of individuals leave for other grids and the remaining interact with others arriving from other grids (the second term); and finally the "visitors" all return home and interact with those who stayed (third term). ${ }^{6}$ We use adjustment factor $w$ of 0.5 to account for the fact that the infection from the commuters happens on a part of the day. ${ }^{7}$ The setup allows for cross-border contagion and has more individual interactions than a simple SIR setup.

\footnotetext{
${ }^{6} \mathrm{We}$ also ignore contamination en route, assuming that individuals are using their own cars and they do not stop on their way. We are also implicitly assuming that an individual visits one place at a time.

${ }^{7}$ We somewhat overestimate the intra-regional contagion as we do not adjust the first term to reflect the fact that individuals who stay in their grid cannot interact the whole day with those who commute. As our objective is to show the importance of cross-border contagion, this simplification is justified.
} 
To illustrate the importance of mobility in the transmission, in a completely symmetrical situation, the diagonal of $C$ has elements $c$ and off-diagonal elements $c^{\prime}$ and the model for each grid is as follows (assuming $w$ of 1 and ignoring indices identifying grids as well as quarantined and recovered):

$$
\begin{gathered}
\dot{S}=-\frac{\beta S I}{N}\left(1+\frac{\alpha K c^{\prime}}{N}\left(1+\frac{S}{N}\right)\right) \\
\dot{I}=\frac{\beta S I}{N}\left(1+\frac{\alpha K c^{\prime}}{N}\left(1+\frac{S}{N}\right)\right)-\gamma I-\frac{t N I}{(N-Q)}
\end{gathered}
$$

The implicit rate of transmission increases with the rate of mobility, that is the ratio of the total number of individuals leaving their region to the total population of the region, $K c^{\prime} / N$ in our notation. Among weakly connected regions at similar stages of the infection, travel restrictions may not reduce contagion substantially, but they will with highly connected areas.

We use a stylized model with 4 grids, each with the same initial conditions and population. Urban planners have long noted that most cities are "monocentric," that is individuals tend to travel to the same place, and usually at the same time (e.g. downtowns or city centers). The OD matrix $C$ we use for the simulations has a major hub (first column) and 3 regions:

$$
\left(\begin{array}{cccc}
85 & 5 & 5 & 5 \\
45 & 45 & 5 & 5 \\
55 & 5 & 35 & 5 \\
55 & 10 & 10 & 25
\end{array}\right)
$$

To assess the path of the decline in the susceptible population, or the increase in the infected, we suggest an assessment metric, or a safety metric to resume normalcy after the lockdown. It compares the implied expected mortality rate in the second phase of the pandemic after the lockdown is lifted to a threshold mortality rate $\mu$ of a known disease such as the seasonal influenza. In the U.S., for example, the population mortality rate of the recent seasonal influenza season was about 0.2 percent. Meanwhile, $\sigma$, the mortality rate of the COVID-19 among the infected is about 1 percent. We use simulations to find the target infection prevalence, $I^{\prime}$, such that in the subsequent second phase, the cumulative of 1 percent of $I(t)$, does not exceed $\mu$, or 0.2 percent in this case. This could be expressed in terms of a relative mortality rate $\rho$ such that:

$$
\rho=\int_{0}^{T} \frac{\sigma I(t)}{N \mu} d t<1
$$

$T$ represents a one-year horizon and $\mathrm{t}=0$ corresponds to the day when the lockdown restrictions are lifted such that $I(0)=I^{\prime}$. In practice, this process can be done recursively by first choosing a preliminary mortality target that is a fraction of $\mu$, corresponding to $I^{\prime}$, then studying the paths of infections in the second phase under different policies and verifying the above condition. 
Assuming that after the lockdown, the number of the infected has been brought down to one in a thousand $\left(I^{\prime}\right)$, we examine the second phase of the epidemic when the lockdown has been lifted and $R_{0}$ (of the original SIR model) goes back to 3 . The number of recovered is at 15 percent. We let the infection rate $\beta$, and ultimately $R_{0}$, go back to its unrestricted level and we compare the outcomes for different testing rates and values of $\alpha$, or travel restrictions. The effective testing rate is 20 percent (with the actual testing rate of about 26.7 percent of population). We compare the number of infected in the standard SIR model (that is, off diagonal $\alpha$ 's are equal to 0$)$, the SIR model with full mobility $(\alpha=1)$, and the SIR model with full mobility and testing and isolation policy (Figure 6).

The simulations show again the possibility of a spike or a second wave of the epidemic. There is a big spike in infections in a model with full mobility compared to a smaller spike if restrictions on movements are imposed. A much flatter curve, closer to a ripple than a wave, is obtained under a policy of testing and isolation. However, the mortality rate even with testing and isolation policy is still relatively high as $\rho$ is equal to 8.2, compared to 77 (standard SIR) and 81.7 (SIR with full mobility). If more tests were available, it would be relatively easy to achieve a lower mortality but in case of rationing, testing could be combined with policies restricting movements across the grids.

\section{Figure 6. Phase Two with Mobility: Number of Infected (Initial $R_{0}=3$ )}

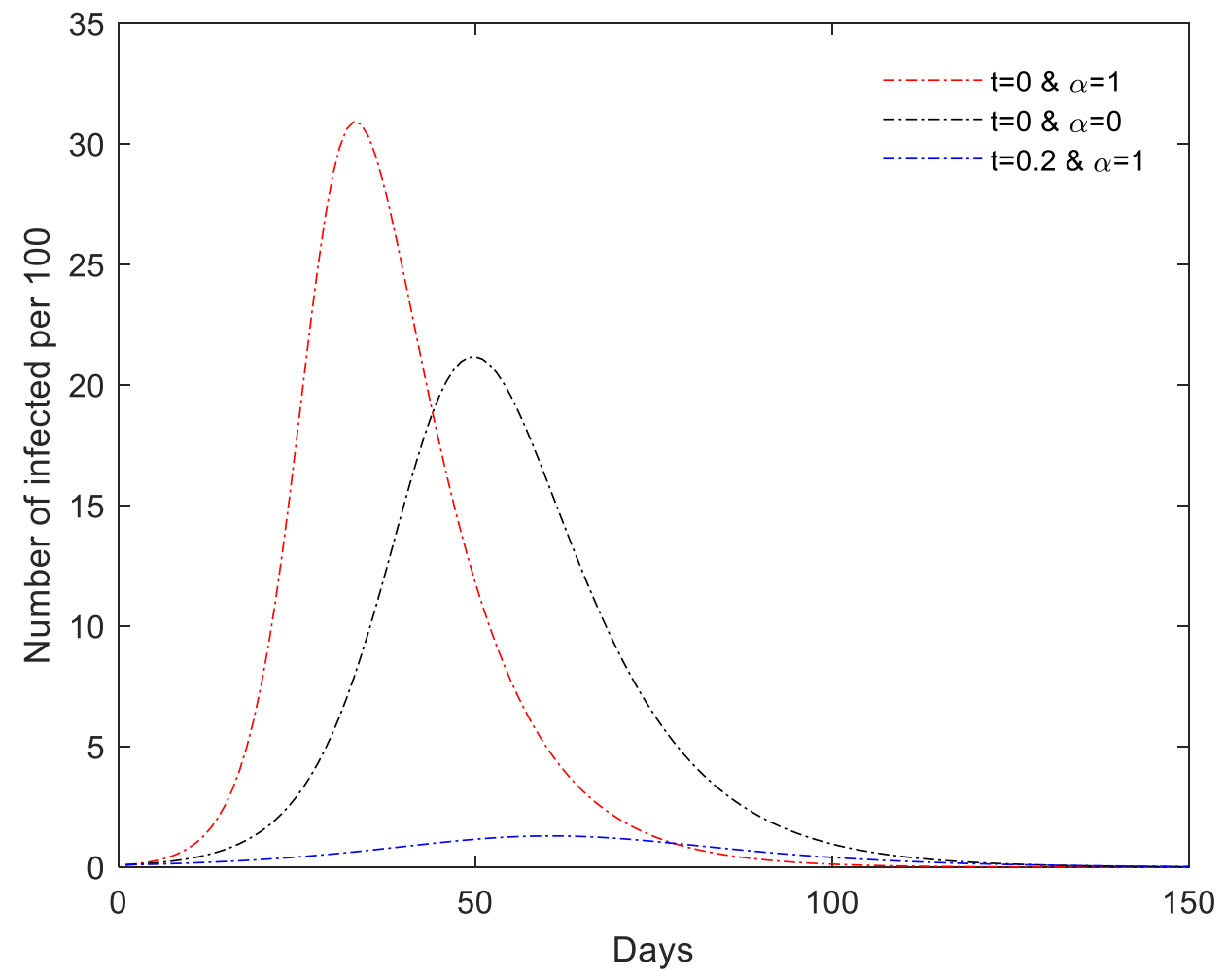

Source: Authors' calculations

Keeping testing and isolation policy in place, we examine the impact of travel or mobility restrictions. We simulate a few scenarios shown in Figure 7: (i) a reduction of movement across the grids by 25 percent (that is off diagonal $\alpha$ 's are equal to 0.75 ); and (ii) restricting 
movement to each grid by 75 percent one at a time while leaving movements across other grids unrestricted (e.g., off diagonal elements of the first column and first row of matrix $\alpha$ are equal to 0.25 while all the others are equal to one). The travel restrictions to the hub are similar to rush-hour taxes imposed on transportation in and out of the downtown in many cities.

The dispersion in the paths of the infected reflect the pattern of movements across the grids, that is the shape of the OD matrix $C$. The peak in infections is the highest when movements to grid 2 are restricted, followed by grids 3 and 4 . Restricting movements across all grids by 25 percent has even lower peak of infections. Ultimately restricting movement to grid $1-\mathrm{a}$ hub-yields a strikingly different result with infections on a declining path from day 1 . In terms of mortality criterion, restricting movements across the grids by 25 percent would result in a $\rho$ of 4.4 while focusing restrictions on the hub would result in a $\rho$ of 1.02 . In other words, a combination of massive testing and travel restrictions that consider the patterns of commuting would yield a mortality rate equal to that of the seasonal influenza.

Figure 7. Travel Restrictions: Number of Infected (Initial $R_{0}=3$ )

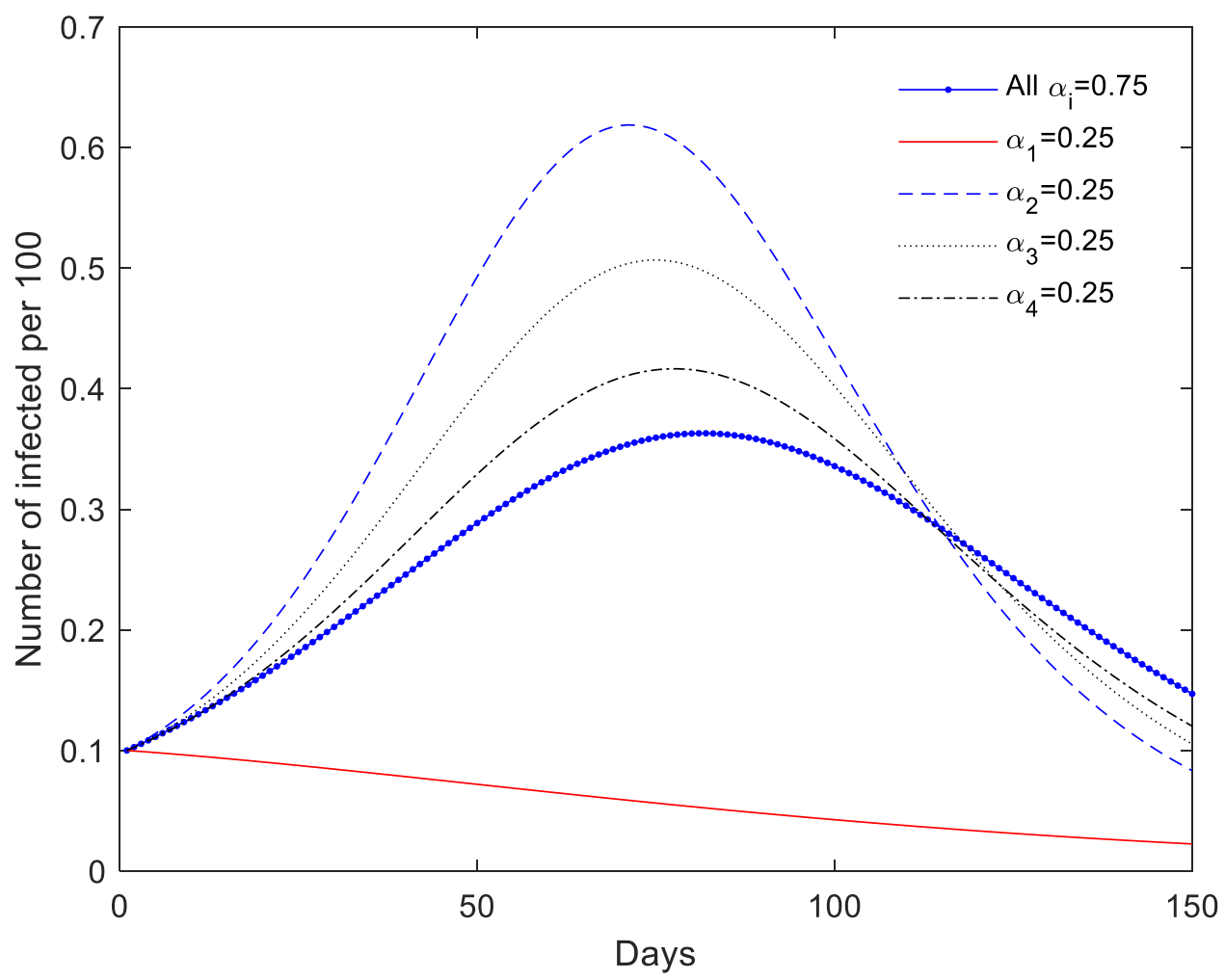

Source: Authors' calculations

The advantage of the strategy that combines testing and isolation and travel restrictions to the hub is that it imposes a relatively light burden on the economy while ensuring a safe exit. Decreasing traffic into crowded city hubs has already been the subject of numerous policy attempts as it has many negative effects, such as congestion and pollution. Achieving this objective could be an unintended positive consequence of halting the pandemic. 


\section{E. Smart Testing Strategies}

We suggest smart testing strategies to optimize the number of tests needed for universal testing, especially when the testing capacity is lacking. Periodic and group testing could substantially reduce the number of daily tests. As illustrated by the model with mobility, dividing areas into geographic testing grids could also help optimize and monitor infection within and across grids. Further complementing grid movement restrictions with social distancing measures and other interventions (e.g. isolation of symptomatic individuals and contact tracing) could help reduce transmission rates as well. These approaches could reduce the number of tests needed from 20 to 30 percent of population to much below 5 percent of the population. However, these measures cannot substitute for universal testing if the objective is to return to normalcy, that is, to open economies in the fastest way possible while minimizing restrictions and keeping the epidemic in check.

Since testing 20 to 30 percent of the population daily would require close to a hundred million of tests a day in the US or billions globally, an effective, relatively cheap and easy to implement way to minimize the number of tests is to conduct periodic rather than random testing. With a 20 percent testing rate, there is about a quarter of a chance that same individual is tested more than once within a 5-day window. ${ }^{8}$ With periodic testing, each person is tested once during the 5-day window eliminating redundant testing. In their framework, Cleevely and others (2020) find an efficiency gain of 37 percent with periodic compared to random testing. In our SIR model, we account for the periodic testing of the population by adjusting the prevalence of infection in the remainder population after each successive day for the duration of the testing window:

$$
\&=\frac{\beta S I}{N}-\frac{t N I}{N-k t^{*} N}-\gamma I,
$$

where $t^{*}$ is the testing rate and $k=\left\{0,1,2, \ldots, \operatorname{int}\left(1 / t^{*}\right)-1\right\}$ is the sequence of non-overlapping rounds of testing. The equivalent in terms of the initial path of infections of a random testing rate of 20 percent is a slightly less than 10 percent periodic testing rate, with efficiency gains of over 50 percent.

Group testing could also drastically reduce the required number of tests especially if the infection prevalence rate is low in the population (Kotlikoff 2020 and Gollier and Gossner 2020). After the lockdown is lifted and the infected share has fallen, group testing could be very effective. Using 384 patient samples and 48 pools, they observed an eightfold gain in testing efficiency (Shental and others 2020). Let us assume we need to test 5000 people split into groups of 10 for a total of 500 groups. Assuming the infected prevalence rate is one percent, any given group (a collection of pooled samples) would test negative with a probability of about 90 percent $\left(0.99^{10}=0.904\right)$. Thus, about 10 percent of the groups would record a positive test. Retesting those 50 groups implies an additional 500 tests for a total of 1000 tests. This is approximately a fivefold gain, or a reduction in the number of tests needed by staggering 80 percent. To generalize, the number of tests needed per group equals

\footnotetext{
${ }^{8}$ Suppose $X$ is the event that an individual is tested. Since 20 percent of population is tested every day, $p^{*}=0.2$. Then, $\mathrm{P}(X>1)=1-\mathrm{P}(X=1)-\mathrm{P}(X=0)=1-(5 ! / 1 ! 4 !) p^{*}\left(1-p^{*}\right)^{4}-\left(1-p^{*}\right)^{5}=1-0.41-0.33=0.26$.
} 


$$
n_{\text {test }}=1+n_{g}\left(1-(1-I / N)^{n_{g}}\right) \leq n_{g} \text { if } \operatorname{Gain}_{g}=n_{g}(1-I / N)^{n_{g}} \geq 1,
$$

where $n_{g}$ is number of people in each group. If the infection rate is low, the number of tests needed for group testing, $n_{\text {test }}$, is much lower than individual testing, $n_{g}$. Minimizing $n_{\text {test }}$ per individual $\left(n_{\text {test }} / n_{g}\right)$ with respect to $n_{g}$ determines the optimal group size. Further reduction in the number of tests is possible by splitting the groups that have a positive case in half, retesting, splitting the remainder in half, retesting, and continuing until the infected individuals are detected (Gollier and Gossner 2020). Although extremely efficient, group testing entails a specific infrastructure to analyze group samples, which may not be readily available in many developing countries. Moreover, gains from group testing are particularly sensitive to the specificity of the test as even a relatively small rate of individual false positives $s$ would increase the number of tests. ${ }^{9}$ Although false negatives reduce the number of positive tests, to be able to meet the objective of identifying a sufficient number of infected, the testing rate of the population needs to increase to compensate for the decline in sensitivity.

Combined with periodic testing, the total gains amount to about 90 percent reducing the number of tests needed from 20-30 percent of population to the order of 2-3 percent of population, provided the test is accurate enough.

The number of tests, especially in the initial stages of exiting the lockdown, could be further optimized by combining the strategy of travel restrictions to the hub with some social distancing restrictions in each grid. Light interventions like maintaining distance in public, wearing masks (Kai and others 2020), checking temperatures (Pueyo 2020), and stronger interventions like staggered work and school times (e.g., 4 workdays followed by 10 home days as suggested by Alon, Milo, and Yashiv 2020) can substantially reduce transmission rates. Contact rates increase substantially in schools and universities, requiring a specific approach. In addition, quarantining the infected outside of their homes would further reduce transmission by preventing household infection (Yglesias 2020). The SIR model with mobility also suggests minimizing trips to local hubs (e.g. grocery stores, large gatherings, etc.). In our SIR models, reducing $R_{0}$ to 1.5 with social distancing measures reduces the number of tests needed. However, over longer periods of time, $\beta$-restrictions on the transmission rates (e.g., strict social distancing, lockdowns, and school closures) apply everywhere and presumably would cause deeper economic damage than $\alpha$-restrictions (travel or movements across grids). For example, an order to close all restaurants and cafes throughout the city for a long time is quite different from restricting movement toward only central districts during certain days or time. Under $\alpha$-restrictions alone, economic activity would be close to normal in each grid most of the time.

In addition to periodic group testing, one could further economize on the number of tests required using what we call "staggered" testing. If it takes time to start testing massively on a country level, one can focus first on key metropolitan centers (e.g. in the US, the top 10 metropolitan areas account for about a quarter of the total population) and then start testing grid by grid within this metropolitan area, focusing on neighborhoods, counties, and urban areas. Once the grid is swept through, those tested negative would continue practicing social distancing or the grid could be partially restricted for travel in and out of the grid. This could

\footnotetext{
${ }^{9}$ In this case, $n_{\text {test }}=1+n_{g}\left(1-((1-I / N)(1-s))^{n_{g}}\right.$.
} 
effectively decrease the pool of susceptible population and eradicate the epidemic even faster. Essentially, part of the susceptible population is also quarantined by applying strict social distancing measures or testing and isolating while on lockdown. As an illustration, we assume a 5 percent initial infected rate, $R_{0}$ of 3 , a 10 percent of population a day testing rate, and a 50 percent of the tested negative essentially stay at home (that is, the isolation of the susceptible). Then, the epidemic is squashed within 20 days instead of 3 months. Thus, testing and isolation policy under lockdown achieves the desired result even faster.

Tackling the virus on a grid could be viewed as assembling the pieces of a puzzle. Each piece could be a local community, a city, or a country. The first implication is that verifying the point of entry becomes relatively easy: everyone at the border could be tested and the infected would be isolated. The second implication is that, if most entries to this puzzle piece are tested while an exhaustive testing and isolation is performed, then it should be virtually free of the virus within weeks and lifting social distancing measures within this area would be possible. Afterward, there is no need for a continuous effort to test everyone at a high rate. Instead, the area selected could then conduct a periodic testing at a lower rate to see if any new infected has slipped through.

Once the epidemic is squashed on the grid, an early warning system could help monitor and control the spread of the infection. The system could help detect and trace early new cases, and, in a worst-case scenario, require moving toward another round of universal large-scale testing (which should be unlikely if the early warning and tracing is done fast and efficiently). Oliu-Barton, Pradelski, and Attia (2020) propose dividing areas into green and red zones and illustrate it could be a beneficial exit strategy. In addition, using alternative methods to detect infection clusters such as testing for the virus in sewage systems, a method used to assess the vaccination campaign against polio (Mallapaty 2020), would be another component of an early warning system. The early warning system could also help monitor cross-grid contagion with some travel restrictions reinstated if needed.

As part of an early warning system with low virus prevalence rates, contact tracing may be used as an additional instrument, but it requires an extreme level of efficiency and more important, it may not be effective beyond the early stage of contagion. At the onset of the epidemic, or very low virus prevalence rates, it is in theory possible to trace the contacts of the infected to halt the epidemic, but it requires an extremely efficient tracing and a fast quarantine or active monitoring of contacts. Kucharski and others (2020) suggest that over 25 contacts need to be traced per newly infected. Taiwan Province of China and Korea have used mobile applications to trace contacts efficiently, but they have done so early on by deploying sizable resources.

With presymptomatic and asymptomatic cases accounting for half or more of the infected, contact tracing relatively quickly becomes a daunting task. There is evidence that the peak of contagion takes place before the onsets of symptoms (Ferretti and others 2020). Even with physical distancing and a reproductive number around 1.5, more than 50 percent of contacts needs to be traced and quarantined, as opposed to actively monitored, to reduce the reproductive number to close to 1 (Peak and others 2020). With $R_{0}$ of 2 , this percentage increases to 75-90 percent of contacts. The use of mobile applications (barring privacy concerns) to identify contacts immediately or with one day delay is also a must to keep the 
reproductive number close to one-and even in this case, about half of the infected needs to be isolated at the onset of symptoms and more than 70 percent of their contacts have to be traced and quarantined (Ferretti and others 2020). A delay of 2-3 days barely makes a dent in the outbreak control. Uncertainty about the share of presymptomatic/asymptomatic individuals and their infectiousness and the possible delayed isolation of symptomatic individuals and their contacts would substantially reduce the effectiveness of the measures based only on the isolation of symptomatic individuals and their contacts.

In addition, tracing, even with the efficient use of technology (assuming most people own a smartphone) and with low prevalence rates, becomes next to impossible in densely populated areas. This may require continuously quarantining a large number of people as a result of high contact rates compounded by potentially large false positive rates (being close in road traffic or behind a wall in buildings), which is less feasible in the urban settings of many developing countries. With many presymptomatic and asymptomatic cases, it is easy to see how hyperlocal clusters of infection, invisible superspreaders, and silent outbreaks would emerge. Even in Korea where contact tracing is efficiently implemented, in combination with many other measures, it has not yet completely contained these outbreaks.

Universal testing and isolation policy is of great benefit even on the smallest scale. If one starts with a town, village, or neighborhood, testing everyone and isolating the infected would restore confidence and help restart social and economic activities in the neighborhood. The town of Vo' Euganeo in Italy with population of about 3300 people sealed its borders and tested everyone twice, before sealing the town and again in two weeks. The infection rate was brought down from 3 percent to 0.25 percent, and once the remaining infected people were isolated, the town resumed activities, and there were no new cases (Zingales 2020). If adjacent towns or neighborhoods would follow suit, it would free movement and economic activity on a greater scale and benefits would be compounded.

Every local effort toward universal testing spills over to other communities as it not only reduces the risks of contagion but also allows resuming economic and social activities. This type of spillover or externality would justify a centralized approach to maximizing the benefits. Once another piece of the puzzle has also performed universal testing, the borders (land or air) between the two could be opened again without any massive testing but with information-sharing in the context of their early warning systems. As more puzzle pieces join in, the number of tests produced could be shifted from the first ones that have moved to an early warning system to potential new entrants that need to perform universal large-scale testing. The number of tests needed could thus be optimized. Other strategies could be explored to prioritize areas according to density and initial level of virus prevalence. This mechanism is also applicable at the country level, and once countries succeed at universal testing, travel restrictions among countries could be eased substantially.

To further ease travel restrictions across countries and support tourism, testing and isolation policy could be applied at the points of departure. One option is to coordinate with airlines and administer rapid diagnostic point-of-care (POC) tests at the departure airport during the check-in with a clause for full reimbursement of the ticket if the test is positive. Hotels in the destination areas could waive cancellation fees and provide reimbursement to those who would test positive and could not fly. This could encourage people to book vacation packages 
knowing that they will either get to their destination safely or be turned away at the airport without losing money (or time in a quarantine in a foreign country). These diagnostic tests would need to have higher accuracy to be effective. Visitors could still be tested during their stay if need be.

\section{F. An Epidemiological Approach to Testing}

In the pursuit of an easily scalable and effective testing technology, a radical shift is necessary from a clinical approach toward an epidemiological or "probabilistic" one. An acceptable clinical test would tolerate very low margins of error, typically less than 1 percent of false negatives or positives, because diagnostics would determine the correct treatment protocol (e.g., PCR-based tests). In contrast, in the context of large-scale testing to contain the epidemic, much greater margins of error could be tolerated implying the possibility of a much cheaper, more convenient, and simpler test to produce. This would require a coordinated approach among scientists, firms, and regulators to distinguish between different types of tests based on their purposes. ${ }^{10}$

The goal of this approach is to isolate rather than diagnose. As argued by Romer (2020a), a testing and isolation policy would be still effective with a relatively high rate of false negatives, up to 30 percent in his example. We use our model to clarify the tradeoffs facing policymakers. As shown earlier, the effective testing rate $t$, was given by:

$$
t=(1-e)(1-z) t^{*}
$$

Where $t^{*}$ is the share of people tested per day, $e$ is the share of people who do not comply with isolation, and $z$ is the rate of false negatives of the test. To achieve a certain level of $t$, for example 15-20 percent in our simulations, policymakers should consider the levels of: $t^{*}$ which reflects the cost, scalability and ease of use of the test chosen; $z$ the quality of the test in terms of false negatives; and $e$ the extent of quarantine compliance. In turn, given a certain $e$, which can be controlled to some extent by policies to ensure enforcement, the choice among test technologies boils down to a tradeoff between quality vs. quantity, or cost vs. precision. For example, if an individual test is cheap and convenient enough to be used by a large proportion of the population, say 40 percent, and assuming that $e$ is 20 percent, then the test used could have a rate of false negatives up to a staggering 37.5 percent. It would still reach an effective testing rate greater than 20 percent, achieving a sustainable squashing of the curve in our model. It goes without saying that such a test stands no chance of being adopted based on a clinical approach alone.

We go further by arguing that in the context of the epidemiological or probabilistic approach proposed, a relatively high level of false positives could also be tolerated. But once the economy is reopened, the cost of the false positives on the economy needs to be taken into account. If the test exhibits a false positive rate of $s$, that is, its specificity is $(1-s)$, then the expected number of susceptible people who would test positive and will be quarantined as a share of the total population, $f$, would be:

\footnotetext{
${ }^{10}$ For example, regulators froze a project in Seattle where people would send their samples from home to be analyzed as a result of inaccuracies in testing (Maxmen 2020).
} 


$$
f=(1-e) s t^{*} S / N
$$

Consequently, if a test has a relatively high rate of false negatives $z$ (or high sensitivity) and low specificity, but it is cheap and easy-to-use, it may not be worth to substantially increase the testing rate since it would imply the quarantine of a sizable number of the susceptible (non-infected) population. Assuming a false positive rate of 10 percent and a share of susceptible equal to 80 percent, for example, $f$ would be equal to about 2.5 percent if 40 percent of the population is tested daily. In this example the cost remains marginal in comparison with the cost of a lockdown.

This insight has deep implications for the type of tests desired and the feasibility of universal testing. A sketch of a perfect epidemiological test would be a test that is cheap, easily scalable, fast to yield results and convenient to use. Ideally, these tests could be do-it-yourself home test kits like pregnancy tests. Minimizing the rate of false negatives and positives (or targeting high sensitivity and high specificity) would be secondary and only necessary for clinical or diagnostic purposes rather than in the context of surveillance testing. The development of scalable, convenient and rapid tests for epidemiological purposes is needed and requires large R\&D funds. ${ }^{11}$ Moreover, current directed state support to produce tests is mostly focused on clinical tests, which is important, but additional support for epidemiological tests is crucial, especially in developing economies as they are cheaper and easier to deploy. As mentioned earlier, in the transition phase and low prevalence environment, symptom-based "tests" to isolate symptomatic individuals could go a long way, but they would result in a quarantine of a large number of individuals that have related symptoms but do not have a virus.

A promising possibility and an illustration of the importance of the epidemiological approach to testing would be the use of serological tests to detect whether a person is in the active infection phase rather than attempting to identify whether a person is in the recovery phase for which they are currently used. The standard view is that serological tests could be useful to detect those who have already acquired immunity so they can resume their normal economic and social activities. The tests detect a type of antibodies (IgG) that develop after about two weeks since the infection. If the share of infected is relatively small, as it is the case in most countries, or if reinfection is possible due to a mutation, then this approach would be of limited use. ${ }^{12}$

Since serological tests are also capable of detecting another type of antibodies $(\operatorname{IgM})$, which develop earlier during the infection, within the first week, including among asymptomatic individuals, these types of tests could fit the sketch of a good epidemiological test. Indeed, some of these tests are intended for rapid testing with results ready within 15 minutes; they cost a fraction of the approved diagnostic tests, about \$2-\$5 (de Walque and others 2020); they are much easier to produce and to scale up; they only require a drop of blood and no

\footnotetext{
${ }^{11}$ Another priority for funding in research would be to focus on infected and asymptomatic individuals to detect early subtle signs of infection that are easily testable, ideally among vital signs. For instance, there is anecdotal evidence of infected individuals who have lower than normal oxygen saturation levels ( $\mathrm{SpO} 2)$ before becoming seriously ill.

${ }^{12}$ However, conducting surveys to know the share of the population who acquired immunity remains important as it is a key parameter in identifying the extent of the spread of the epidemic.
} 
special swabs to collect samples; and they can be done using strip-based assays similar to home pregnancy tests. The challenge with these tests is that they do not meet the standards of clinical tests in terms of sensitivity and specificity (false negatives and positives) in particular for identifying active infections. The accuracy of the tests improves with the passage of time since the infection or the symptom onset. As a result, these tests are not considered for mass testing on clinical grounds. However, using different rapid tests on the same individual may improve accuracy.

Serological antibody tests are only one possibility, and rapid antigen tests and point-of-care rapid molecular tests could be potentially used for epidemiological tests. The development of cheaper and easy-to-use epidemiological versions of other types of tests (e.g., genetic tests), that have the same principle but allow for lower sensitivity and specificity to achieve greater scalability, would be encouraged. Moreover, given the scale of the task, it could make sense to produce and use different types of tests at once so as not to strain the value chains. Rapid point-of-care tests could provide an avenue to achieve the needed amount of testing while minimizing false positives and negatives. These are relatively fast and easy to use but require some lab equipment (Egilmezer and others 2018).

Despite the massive amount of test kits needed to implement rapid and universal testing and isolation strategy, the cost of doing it is still dwarfed by the cost of the lockdowns or the second wave of infections. The quick recovery due to rapid and universal testing would not only reduce the current output losses but would also reduce the probability of permanent losses and thus huge potential costs. Our simulations suggest that testing 20-30 percent of population would suffice to squash the epidemic and reopen the economy. Smart testing such as periodic testing could reduce the testing rate to around 10 percent. We a priori rule out combining group testing with relatively low accuracy epidemiological tests as the gains may be lost due to relatively high rates of false positives.

Nonetheless, the cost of testing a large part of population is relatively small. With the cost of administering each test for about $\$ 5$ (de Walque and others 2020), which is on the high side of the per unit cost estimates, on a global level with a population of about 7.7 billion people, this strategy would amount to about 23 billion tests a month (equivalent to 10 percent periodic testing of the population daily) with a cost of about 115 billion dollars a month, which is less than one week of the global output loss. Alternatively, with diagnostic group testing (periodic testing combined with group testing equivalent to 5 percent of population daily), the cost of which is estimated to be about $\$ 20$, including related costs (de Walque and others 2020), the total cost would amount to about a quarter of trillion dollars a month, which is still below two weeks of the global output loss. With test kits potentially costing \$1 in the works (Bradley 2020), the total cost of the testing and isolation strategy could amount to only a fraction of a loss of the monthly global output. Most likely, economies of scale would lead to extremely low costs per unit once production is ramped up globally. As many observers have pointed out, globally, about 2.8 billion cans of soft drinks are consumed daily (Statista 2020), which are a major contributor to obesity, heart disease, diabetes, among others. A discussion as to whether universal testing is worth the cost or whether it is doable seems frivolous if framed in this light. 


\section{MARKet FAILURES IN Testing Times}

The provision of tests and other critical medical products should be easily met in the context of a standard supply-demand model with perfect competition, perfect information, immediate and costless adjustment, and no capacity constraints. In this theoretical case, the market would provide all the needed products at an equilibrium price reflecting both technological constraints and preferences. In normal times, the market for critical medical products such as test kits would be broadly in equilibrium in most countries. However, amid the ongoing pandemic severe shortages of medical goods have appeared, and the lack of tests has become the critical bottleneck toward a decisive defeat of the virus. We argue that during a pandemic the market could cease to provide the quantity of test kits that society would require, leading to severe rationing and welfare losses. We outline the policies and institutional apparatus needed to tackle these market failures.

\section{A. From the Invisible Hand of the Market to the Leading Hand of the State}

\section{The inefficiency of the market during a pandemic}

The lack of competition is an exacerbating issue but not the binding constraint in the context of a pandemic. Monopolists or oligopolies would choose a smaller supply and higher price compared to a market supplied by price takers with the equilibrium quantity most likely lower than the quantity needed. Yet the central issue is the capacity constraints faced rather than the market structure. If the capacity to produce all the needed tests existed, issuing regulation for monopolies to increase production to the needed level or the ramping up of production by competitive firms, irrespective of the initial market structure, would potentially solve the shortage of medical goods. Even if some consumers (e.g. hospitals) are being rationed because of higher prices, various support schemes could be designed to meet the needed production levels at existing prices (e.g. government subsidies to firms or consumers).

However, leaving existing firms in the driver's seat of the market certainly raises the question of the feasibility of a rapid ramp up of production. The procurement of a huge quantity of medical goods at a price set by the state, as we argue below, would not necessarily maximize their profits. More important, when asked if it were "feasible" to attain a certain production target within a short period of time, firms would refer to their standard market objective of maximizing returns to answer it (with most likely no). In the world of maximizing efficiency to minimize costs ("just in time" delivery) rather than factoring in redundancy and resilience of value chains makes it even harder to scale up relatively quickly. Resilience may not be much factored into the production decision of a firm despite being valued on an industry level in case of unexpected large shocks. The market logic of tackling uncertainty, maximizing earnings, minimizing costs, and accounting for constraints on the inputs and logistics is certainly a guide in "peace" times. The choice of technology could also be influenced by a profit-maximizing motive and run contrary to the need for a simple design and ease to produce and operate. For instance, this has been a major concern in the ability to stockpile and ramp up the production of ventilators (Azmeh 2020).

Facing such an urgent crisis by completely relying on the workings of the market is imprudent as the market is riddled with market failures and cannot resolve many of the hurdles faced. Even if the market attempted to ramp up production relatively fast, most likely capacity 
constraints would be hit due to the huge demand shock. Only with the large resources and coordinating ability of the state could both public and private resources be combined for a common goal. There is a need for coordinating among different actors of the production value chain, overcoming administrative and regulatory hurdles, considering the social benefits rather than the narrow profits of firms, enforcing accountability for the support received, deciding on the best production technology, etc. This critical moment requires the leading hand of the state (Cherif, Hasanov, and Zhu 2016).

\section{The fog of uncertainty}

In the face of uncertainty firms may not invest enough in the capacity needed to meet all the demand. One of the reasons for the shortage in masks, ventilators and test kits in many countries is the fact that firms could not have predicted the scale of the increase in demand. Even if they could have somehow anticipated it, they might not have invested enough ex ante to meet the demand of a tail event. Many firms are scaling up their production in response to the spike in demand. However, investment is costly and the prospects of demand over the months ahead remains largely uncertain, especially in terms of test kits. There are many factors that are difficult to predict such as how long it would take for the virus to disappear, how many people would be infected, and which technology would be picked for mass testing.

Given the asymmetry in the cost-benefits tradeoff, firms would always prefer to err on the conservative side, preferring to take the risk of rationing the market rather than the risk of flooding it with extra supply. Firms may still remember that after the 2009 H1N1 flu pandemic, major pharmaceutical firms ended up with excess capacity to produce vaccines when the virus faded, resulting in large losses (The Economist 2020b). A heightened uncertainty increases the likelihood of underprovision by the market.

For the nascent test kit market, there is an additional layer of uncertainty related to the technological choice. Not only are firms unable to predict the extent of the market, they run into the risk of betting on the wrong type of test especially in the context of mass testing where the state might choose a limited set of technological solutions to be scaled up. Moreover, as we argued earlier, the lack of distinction between tests for clinical and epidemiological objectives may discourage investment in the most scalable technologies, hampering the effort to halt the epidemic.

\section{Race to the swift}

In theory, if the demand increases, because tests have become critical products, supply would eventually increase to reach a new equilibrium at higher quantity and price. Even if we assume that the new equilibrium could be met with all the tests needed to defeat the virus, the key issue is how long it would take for supply to increase to meet the necessary demand. There are many constraints that would delay a swift ramping up of production.

One of the key constraints to substantially increasing the production of test kits is ramping up the production of the whole value chain. The shortage in critical inputs due to uncertainties, capacity constraints, and other hurdles could potentially derail the effort. There is a need for foresight and coordination at every level of the value chain (e.g., chemical reagents, swabs, 
logistics) to quickly add the needed production lines, equipment, and workers (which is harder during a pandemic). And without the resources and coordinating role of the state, many of these supply constraints may not be overcome.

Not only the standard long regulatory approvals for medical goods production but also other business regulations need to be expedited. This is particularly important in terms of test approval, but it covers a wide array of activities such as hiring workers, expanding existing facilities or building new ones, and importing critical machinery or inputs. A one-stop shop with power of expediting and resolving all these challenges is needed.

Lifting barriers to entry or encouraging "forced" entry could be necessary to increase production quickly. Involving new entrants could be needed along the expansion of existing firms. A main barrier to entry consists in intellectual property (IP) rights and knowledge of production processes. In this regard, IP and production process knowledge related to test kits should be provided to all the firms producing the product and its inputs. The state could design various mechanisms such as patent pooling to compensate the IP holders and reward adequately innovation while reining in patent trolls (Stiglitz, Jayadev, and Prabhala 2020). If firms do not comply, invoking compulsory licensing (allowed for pharmaceuticals by the World Trade Organization, especially during emergencies) may provide a credible threat for firms to cooperate. In addition, taking advantage of already existing production capabilities and trained staff in related industries, requiring existing firms to re-orient some of their production capacity toward the production of test kits, could be necessary. Both large firms with their enormous ability to plan and execute complex logistical chains and small firms with their agility and entrepreneurial spirit would be called for action. There is a strong economic case for "forced" entry. If production is not ramped up fast enough, the whole economy suffers from not only temporary output losses and larger unemployment but also greater risk of a persistent depression and potential civil turmoil. There is a positive externality of contributing to the universal testing effort, which cannot be captured by an individual firm. By mandating firms to participate, the state can tackle this type of market failure.

The ramp up in production would not necessarily result in a sunk cost in case the virus disappears by a cure, vaccine, or "miracle." Even if the virus disappears by "miracle" in the short run, as a result of mutation, for example, the world should still need to urgently develop and maintain a massive production capacity of tests as part of the epidemic preparedness. In the face of the future pandemics, deploying a test would be the best line of defense. It is much faster than creating a vaccine or an anti-viral drug, and it would avoid long and costly lockdowns. In addition, in a pandemic, potential "overshooting" of production of tests should not be an issue. Since the successful mitigation of the virus in other countries would help lower the risks at home, there is very little likelihood of unused production as there is a limited production capacity in many low-income countries. There is also a good case to subsidize or donate the tests to lower-income countries, especially by neighboring countries or those with strong ties to a home country (e.g. through trade and immigration).

\section{Demand for tests: Free and mandatory for all}

Even if the constraints on supply were lifted, the market demand might not necessarily result in universal testing even if testing were free. As discussed above, the amount of testing 
needed per day implies a large ramp up of production. Let us assume that the constraints on supply were all tackled, and the supply can meet the necessary demand. If everyone is simultaneously internalizing the benefits of universal testing and is willing to pay a relatively high price for the test, then there would be no need for an intervention. A person paying for a test would find it beneficial only if essentially everyone else would do the same to be able to safely interact with others - an externality of testing. The more affordable the test is, the more likely it is to get more people tested. Yet even if the test were free, it would still require consumers and others to voluntarily get tested, and demand for testing may be lower than required. Internalizing the benefits of other people getting tested may not happen fully in the market and coordinating voluntary testing may be complicated even in a repeated setting. Ultimately, the most reliable solution consists in imposing a compulsory and free test for all to resolve a coordination failure, positive externality, and price rationing. Some compliance mechanism to monitor enforcement is needed - a proof of testing for jobs, building entry, etc.

\section{B. Sketching a Strategy}

The challenges and constraints discussed, which the market, even a highly competitive one, would fail to address illustrate a sketch of state policies needed. The strategy is based on the "True Industrial Policy" (TIP) principles of setting ambitious goals, building capabilities and adapting fast, engaging the private sector, and providing necessary support while ensuring accountability (Cherif and Hasanov 2019). Many features of the strategy sketched below are followed in advanced economies to some extent, albeit without the same focus and speed. Moreover, these features are barely applied in developing ones. The strategy can be summarized along the following lines:

- Objective: A clear and ambitious objective (e.g., select a scalable epidemiological test for 20-30 percent of the population a day for free and mandatory) is needed with numerical targets (e.g., produce tests on the order of 5-10 percent of the population a day), deadlines (e.g., by end-month) and an endgame (e.g., virus free within 2 weeks and relying on an early warning system thereafter).

- Institutions: The state needs to set up a taskforce responsible for ramping up production and directly reporting to the high-level council in charge of applying the strategy and involving major actors across government agencies and levels (e.g., central, regional), and the private sector with regular meetings and communications to the public. The key agencies such as science, treasury, central bank, development bank, and others would be part of the council.

- Incentives and accountability: The task force should have the authority to change the incentives (e.g., moral suasion, tax breaks, financing) and enforce accountability (e.g., quality and quantity) for firms once the clear objectives have been agreed with them. It would run the operation and coordinate across firms, the value chain, and government agencies. The access to financing would be provided (e.g. via a development bank).

Dealing with all these challenges calls for a collaboration among firms and policymakers to reduce coordination and informational frictions and gain speed. While the main mechanism of the market is competition, in the crisis times, there is a need to shift toward collaboration. 
Information-sharing among firms concerning production processes, technology, and resources would help combine efforts to solve common bottlenecks and learn from each other. It would particularly support new entrants to learn from incumbents. Setting up informal and fast information-sharing forums at different levels of the firm (e.g., R\&D personnel, engineers, technicians), using industry associations and public-private industry alliances would contribute to knowledge flows, coordination, and collaboration.

The incentives could be put forward by the government to encourage collaboration. The SEMATECH alliance of the US semiconductor companies in the 1980s is an example of the public-private industry alliance in support of the US semiconductor industry. Others have proposed a more direct intervention to create "Pandemic Testing Board" that takes its name and function from the WWII's war production board (Maier and Kumekawa 2020). Yet another approach could be what the Federal Reserve Board of the U.S. did during the 2008 financial crisis, in which it used its crisis powers to coordinate among banks, bring them into one room, and organize bailouts and liquidity support. A high-level policymaking agency could take on a similar role in fighting the pandemic crisis.

Producing a few hundred billion of test kits a year globally may seem like a staggering number, but the world has been producing billions of various medicines and consumer goods. For instance, in the US, in 2012-2013 about 39 million people have used statins against high cholesterol levels, amounting to 221 million prescriptions and probably about tens of billions of pills a year (Salami and others 2017). Johnson \& Johnson is producing about 5 billion contact lenses a year (Johnson \& Johnson 2019). In 2018-2019, about 170 million flu vaccines were distributed in the US and much more globally (CDC 2019). In the consumer goods markets, in 2019, about 128 billion cans of soda were produced in the US and about a trillion cans globally (Statista 2020). About 2.1 billion smartphones, tablets, and personal computers, including 1.5 billion smartphones alone, were shipped globally, which are much more complex products to produce with a lot of complex inputs (Gartner 2020 and Lunden 2020). With a cost of a few dollars per test, the production of test kits would be about equal to the global pharmaceutical market, about 1.4 trillion dollars, not a trivial increase but still a small fraction, about one and a half percent, of the global output (The IQVIA Institute 2020).

A good example of what could be achieved is seen in the efforts of advanced countries to prepare the supply of a possible vaccine in the race against COVID19. The pharma companies are ramping up production to get ready to produce hundreds of millions of doses with manageable cost. "Operation Warp Speed" of the US government has set a goal of 300 million vaccines to be ready by early 2021 . The government funds have been flowing to biotech and pharma companies to expand production. A Boston-based biotech company Moderna has received about $\$ 500$ million to expand its facilities to produce tens of millions of vaccines a month by 2021. Manufacturing hundreds of millions of doses would cost firms with existing facilities and personnel about $\$ 50$ million, reaching $\$ 700$ million for the new facilities, according to Gavi, a vaccine alliance (Miller and Kuchler 2020). On a global level, much larger production is needed both for a future vaccine and more immediately, test kits.

To achieve success, incentives must be aligned, and accountability has to be enforced. The objectives and accountability for all the relevant actors should be clearly set. The relevant agencies in charge of regulation and administrative issues (e.g. agencies regulating medical 
products) need to switch to an emergency mode operation. It should have the responsibility of not only doing quality control but also helping firms meet the needed requirements within the shortest time possible. It should also act as an information disseminator as to how to reach the quality standards. The same applies to the firms involved in the production chain of test kits. If the production target such as the number of test kits, amounts of inputs needed, or specific infrastructure required, is clearly specified, incentives would be aligned and accountability can be enforced. A mechanism to share the burden among firms and potential incentive mechanisms to compete and collaborate (e.g. prizes and various financial incentives such as tax breaks and loan guarantees) could also be considered as the success of the firms involved would benefit the whole economy. A high-level government task force would coordinate the production orders and information flows.

In addition to production, the whole testing infrastructure needs to be planned out. Deploying tests en masse requires logistical support, potential quarantine facilities (and financial support for the quarantined) and may face bottlenecks depending on the selected test technology. For example, if a test requires face-to-face interaction to collect samples (e.g. rapid POCT), enough protective gear should be made available for the testing centers. Enforcing the isolation of infected people in a quarantine would require similar planning. Similar to voting, testing a large part of the city or country's population daily can be done using the facilities and parking lots of schools and community centers, making the task manageable.

\section{Learning from the WWII's Production Ramp Up}

Although a huge ramp up in global production of medical goods, including test kits and its inputs, is urgently needed, it is a fraction of the production ramp up during the WWII mobilization in the US. In the August 20, 1945, issue Time reported: "In the five years since the fall of France, U.S. industry and labor had turned out: 299,000 combat planes (96,000 last year); 3,600,000 trucks; 100,000 tanks; 87,620 warships (including landing craft), 5,200 merchant vessels; 44 billion rounds of ammunition; 434 million tons of steel; 36 billion yards of cotton textiles for war" (Waxman 2020). In those few years, new technologies were invented, new industries were started from scratch, hundreds of factories were built and expanded, productivity skyrocketed, and labor force increased. Government spending reached about 40 percent of GDP from less than 10 percent in the 1930s (Bossie and Mason 2020).

Like Kennedy's call for a moonshot a couple of decades later, the goal the president Roosevelt put forth before the nation was ambitious and seemed insurmountable. In his fireside chat on May 26, 1940, he said that the US needed to produce 50,000 combat airplanes in the next year when it barely had 3,000 mostly obsolete planes and it had not produced this amount, even cumulatively, since the first flight of the Wright brothers in 1903 (Trainor 2019). Three years later, the US was producing more than 50,000 combat airplanes, a 30 -fold increase from the 1940 level. And airplanes were only part of what was needed for the mobilization effort. The construction of Liberty ships went from about a year (from keel laying to delivery) to less than two weeks (and even a few days in some cases) within a couple of years at Kaiser's shipyards (Tassava 2003).

Pushing for ambitious targets and inflating the requirements on the production needed, Roosevelt famously quipped to his advisor questioning the numbers: "Oh, the production people can do it if they really try" (Zeitlin 2020, Klein 2013). William Knudsen, the president 
of General Motors who became Roosevelt's force organizing and coordinating mass production as the director of what later became known as the War Production Board, said: "We won because we smothered the enemy in an avalanche of production, the like of which he had never seen, nor dreamed possible" (This Is Capitalism 2020).

To meet Roosevelt's call to ramp up production needed a different approach than the marketdriven approach tried and failed during WWI. Then the war mobilization was essentially driven by the private sector. Only 10 percent spent on new plants and equipment in 1917-18 was provided by the government. Although the War Industries Board, overseen by the Wall Street financier Baruch, managed to mobilize production, it catered to major corporations, and war profiteering was extensive (Rosenblatt 2018a). Decentralized purchasing led to bidding wars among military units, production delays, and hiked prices (Brunet 2020). On the other hand, risk was still largely borne by the private sector as many contractors were left with unwanted goods when the government canceled orders after the sudden end of the conflict in late 1918 (Wilson 2020).

The approach Roosevelt took at the wake of the war was for the state to take the lead in the mobilization effort. Roosevelt knew he needed industrialists at his side to meet the gargantuan increase in demand at each stage of the production chain. He called Knudsen and asked him to lead the effort and bring industrialists onboard. Knudsen came to Washington, went to his hotel room and two days later produced a plan to turn the US into the global manufacturing powerhouse within 18 months (This Is Capitalism 2020). Roosevelt created several agencies to oversee various functions of production and finance with limited and overlapping powers and responsibilities (giving him brokering and decision powers), put in charge capable leaders, and relied on them and the private industry to do the job. When agencies or leaders faltered, they were quickly replaced with others to carry on (Hone 1991).

The agencies were instrumental in achieving the ambitious goals set. One of the key agencies was the War Production Board (WPB) that managed and coordinated production chain. WPB matched production orders with interests and capabilities of firms and tasked large established firms with more complex orders. Another key agency was the Reconstruction Finance Corporation (RFC) that financed operations. It was a Hamiltonian-style national bank and was instrumental in directing credit during the New Deal (Rosenblatt 2018a). There were also specialized agencies tasked, for instance, with developing synthetic rubber industry. The National Defense Advisory Council, established by Roosevelt, served as a coordinating body across all the agencies.

The state used various tools and incentives to have the private sector step up production substantially and quickly. Initially tax credits and incentives were tried but had limited success as the projects were mostly of safe nature. So was the program (Emergency Plant Facilities) that reimbursed firms in the future for building plants thus requiring a large initial investment from the private sector. Despite the future reimbursement, the private sector was reluctant to take on huge upfront costs. Loan guarantees - the V Loan Program - worked relatively well as they tripled the bank lending to war industries to about 18 percent of bank loans in 1943. However, they accounted for a small share of total war financing. 
The Defense Plant Corporation (DPC), that was a subsidiary of RFC, began directly investing to build factories and financing industries. It would then lease built factories to firms for a notional one dollar per year and cap the profits at a fair and reasonable amount (after the war, firms had an option to buy factories back, but the state retained production rights when needed). These GOCO_-government-owned, contractor-operated_plants were a key mechanism of expanded production. Through the war, the federal government had contributed directly two-thirds of the total invested, ending up owning large, and in many cases majority, shares of the US heavy industry (Bossie and Mason 2020).

Securing demand for orders allowed firms to ramp up production. The ramp up of machine tools industry made up of many small specialized firms illustrates this point. The tools were a key input in the production of aircrafts, tanks, trucks, and other equipment, and each factory required tens of thousands of tools. A huge shortage of machine tools prompted DPC to create a pool of guaranteed machine tool orders and finance it, spending about $\$ 2$ billion during the war (about \$28 billion in 2020 dollars). Production increased tenfold to about 300,000 machine tools per year from 1938 to 1942 (Rosenblatt 2018b). More important, DPC placed orders in the pool even before the specific buyers were known to expedite the production process (Bossie and Mason 2020).

The "leading hand of the state" played a crucial role in creating new industries such as synthetic rubber industry and increasing supply of raw materials. As the supply of natural rubber from Asia, a key input in many industries, was disrupted by the war the DPC invested $\$ 700$ million (about $\$ 10$ billion in 2020 dollars) to build 51 plants to produce 700,000 to a million tons of synthetic rubber a year. The production increased by 3000 percent between 1941 and 1945 (Bossie and Mason 2020). In addition, the federal government also provided funds for R\&D for both basic and applied research. Even in the initial stages of development, the DPC provided seed money to chemical companies to develop synthetic rubber, and the licenses were shared with other producers (Rosenblatt 2018c). The state essentially owned the industry well into the mid-1950s. Similarly, the large shortages of raw materials such as aluminum, copper, and other metals that were needed for the production effort were addressed by the Defense Supply Corporation, another subsidiary of the RFC. For instance, aluminum production increased from about 400 million pounds a year in 1940 to about 2.25 billion pounds a year in 1943 with over half of the output produced in the facilities built by DPC (Rosenblatt 2018d).

The transformation of the auto industry in shifting production to the military needs was also remarkable. While more than 3 million cars were produced in the US in 1941, only 139 were manufactured during the whole war (PBS 2020). The task was enormous despite the fact that three-quarters of financing for the airplane development came from the DPC (Rosenblatt 2018c). For instance, Chrysler discovered that a prototype of a tank with 3500 parts required about 200 pounds of blueprints (Rosenblatt 2018b). When Ford was tasked with producing B24 bombers, the car of the day had about 15,000 parts and weighed 3,000 pounds while the B24 had 450,000 parts and 360,000 rivets in 550 sizes and weighed 18 tons. $^{13}$

Many doubted Ford could build the whole airplane, but Ford proved them wrong. The famous Willow Run plant at its peak produced a B-24 bomber every hour, day and night. At the

${ }^{13}$ Some estimates of the number of parts are close to 1.5 million (PBS 2020). 
beginning of the venture, Ford's production chief overnight designed an assembly line that emphasized standardized interchangeable parts and orderly continuous flow like that of the auto assembly. His team disassembled the two planes flown in and came up with the blueprints needed. 42,500 employees were working at the plant, but the mass assembly had not begun until the year after the factory opened as all the bottlenecks such as housing, essential input specifications and input delivery, and labor relations, had to be fixed. To deal with continuous modifications to the plane and avoid costly factory shutdowns, many parts were outsourced to about 1000 Ford factories and independent suppliers so that the Willow Run factory could operate under more predictable conditions (Trainor 2019).

The enormous and fast ramping up of the production of a large number of sophisticated goods required for the war mobilization suggests a few key lessons. First, the effort has to combine the coordinating and financing role of the "leading hand of the state" with the production capabilities of the private sector. Second, a high-level council with key state agencies needs to be set up to drive the agenda that has to establish ambitious and clear targets, specify accountability framework with deliverables, profit margins, and labor relations, coordinate information flow across agencies and firms, provide for sharing of designs and intellectual property among firms, engage all capable firms to allow for competition and potential failure, and clear up bottlenecks in supply chain and regulatory regime. Competency and talent of leaders in charge cannot be more emphasized. Third, to reduce uncertainty and risk for firms, demand has to be guaranteed and financing has to be sufficient and, in many cases, it may involve a direct ownership of facilities such as GOCO plants to ensure the provision of critical inputs in the value chain. Lastly, it was continuous effort and ingenuity of many firms and workers, including civil servants in government agencies, that worked together to reach the goal in front of them while removing all the obstacles on their path.

\section{Why Most Developing Countries Should Follow TIP Now}

There are several reasons justifying why most countries, including developing ones, should start working on developing a productive capacity in tests. There is a huge gap between the quantity needed to achieve universal testing and current production in advanced countries. It may take a long time for developing countries to access imported test kits. There is also no guarantee that advanced economies would follow the above strategy and ramp up their production sufficiently. This could lead to a dystopian situation where some parts of the world, mostly advanced, would be open to business resuming relatively free movement among themselves, while the rest would be fighting for the limited supply of tests. Most of these countries might not succeed at joining in and could face repeated lockdowns and potentially huge loss of life and suffering. Defeating the virus through testing depends critically on the ability of each country to access the needed tests quickly and the only effective way to achieve it is through developing its own production capacity. More important, this know-how would also lay the ground for the ramping up of vaccine production when a vaccine is found and for building pharmaceutical and manufacturing capabilities.

Emerging economies have a relatively higher chance to succeed at this endeavor than lowincome countries as they already have the needed human capital, industrial knowledge, and financing. But even smaller emerging market and lower-income economies could coordinate regionally to share the costs and human capital to produce the needed tests with the technical and financial assistance from other economies. In additional to regional cooperation, 
international organizations could provide further technical and financial support. The good news is that the universal testing and isolation strategy is easier to implement for a small population.

As to the question if they could do it or it would be too costly and time-consuming, cheap and fast tests are already in the works. There are tests being developed that are technically simple, akin to pregnancy tests, and cheap and do not require complex equipment or even electricity to provide the results. In terms of the industrial scale, for example, soft drink companies already produce more than 100 million drinks a day on the African continent.

Even innovation could come from developing economies with experience in fighting past pandemics such as Ebola. For example, a test invented by the Senegalese National Institute for Health and a British biotechnology company (Bradley 2020) could cost as little as a dollar per test. Not only can low-income countries in Africa and elsewhere produce at an industrial scale, they can also innovate on adapted technologies laying the ground for a recovery and manufacturing renaissance and paving the way for sustained long-run growth.

Finally, one could argue that for many low-income countries with low capabilities and urgent needs across a wide spectrum, engaging in industrial policy to produce test kits could be a luxury they cannot afford, although it may eventually more than repay the spent resources by creating new industries. The answer would depend on the true cost of such a policy, which could be relatively low even for low-income countries that need to diversify their exports and economies, and whether the prospect of a severe and resurgent pandemic with devastating effects is taken seriously enough.

\section{Conclusion}

The simulations using SIR models clearly indicate the efficiency of large-scale testing and isolation. It is the only viable strategy to indefinitely "squash the curve" while allowing for major economic activities to resume. To implement this policy on the global level, less than a billion of tests per day is needed. Yet, because of economies of scale, the cost of production of these tests could end up being a rounding error compared to the colossal cost of repeated lockdowns or the uncontrolled spread of the pandemic.

It may seem like an insurmountable task, but it is in fact largely achievable provided policymakers adopt an epidemiological approach to testing. It implies potentially trading scale for accuracy, for instance through the use of serological tests (IgM tests) or convenient, cheap, and rapid molecular or antigen tests. For example, a $\$ 1$ test that can be performed by anyone at home and produce a result within minutes would largely compensate for less than ideal, and clinically unacceptable, sensitivity and specificity features of the test. This type of test would be particularly useful for developing economies. A smart testing strategy with universal periodic group testing of large parts of population, especially in densely populated areas, would need to be put in place. Light social distancing and travel restrictions to a city's hub would decrease the number of tests needed while keeping economic activity largely undisturbed in each grid. Moving to an early warning system comprising continuous testing on a smaller scale, tracing, and isolating could be contemplated until a vaccine is found. 
We argue that the market alone cannot ramp up production of test kits and other medical goods fast enough without a clear support and coordination from the state. Market failures stemming from market power, externalities, short-term profit goals, and coordination challenges as well as capacity constraints triggered by the pandemic shock would be unsurmountable for the private sector alone. The state with its strong role of coordination as well as a command of large resources can direct the power and ingenuity of market forces to ramp up production of test kits and critical medical products.

To achieve a universal testing and isolation scheme globally requires applying the principles of a "True Industrial Policy" (TIP) strategy especially in developing countries. Policymakers would implement policies to tackle the market failures riddling the production of medical products. State intervention in this context can also draw lessons from war mobilization efforts albeit at a minuscule scale in comparison. The TIP strategy needs to set an ambitious goal in terms of the number of tests produced. A task force at the highest level of the government needs to coordinate among all the key stakeholders in public and private sectors to tackle bottlenecks (e.g. regulation, supply chain, distribution, etc.). Large firms as well as innovative small firms have to chip in this endeavor. Sharing information and knowledge would expedite the process. The state needs to provide support to firms but must make firms accountable for the goals agreed upon. The resources spent on this endeavor cannot compare to the costs of high unemployment and potential social unrest and even starvation of the poorest in developing countries. As the US President Franklin D. Roosevelt said, "Powerful enemies must be out-fought and out-produced."

Ramping up the production of test kits and other medical gear in developing countries is even more urgent. Doing so would not only stimulate production and growth in the short run when major service sectors are suffering but also pave the way for the manufacturing of vaccines in due time. This production mobilization would also be an opportunity for developing countries to refocus their resources from non-tradable services back to manufacturing, reversing "premature deindustrialization" and paving the way for sustained growth due to the creation of manufacturing capabilities.

Scientists have been predicting that novel infectious diseases will appear at an increasing frequency as a result of climate change and deforestation (Afelt and others 2020). Even if a vaccine or a cure is found for the SARS-CoV-2 virus or if it miraculously disappears, executing this strategy is still necessary and urgent as an insurance policy against future pandemics. It should be considered as an investment to build a testing and isolation infrastructure, which should be maintained as part of the pandemic preparedness. As modern cities have been building and maintaining sanitation infrastructures since the middle of the $19^{\text {th }}$ century to protect their inhabitants from another epidemic threat, cholera, the cities of the $21^{\text {st }}$ century would face coronaviruses or other potential infectious diseases with testing and isolation infrastructure. ${ }^{14}$

\footnotetext{
14 The ravages of cholera in the first half of the $19^{\text {th }}$ century and the discovery by Dr. John Snow and Reverend Henry Whitehead that the disease was waterborne played a crucial role in the decision by the city of London to commission the construction of its sewage system, which is to this day one of its biggest and most enduring infrastructure feats (Johnson 2006). Other cities in Europe and elsewhere followed suit, vanquishing cholera in modern societies.
} 


\section{REFERENCES}

Acemoglu, Daron, Victor Chernozhukov, Ivan Werning, and Michael D. Whinston. 2020. “A Multi-SIR Model with Optimally Targeted Lockdown.” NBER Working Paper 27102.

Adam, Dillon C. and Benjamin J. Cowling. 2020. "Just Stop the Superspreading." The New York Times. June 2. Available: https://www.nytimes.com/2020/06/02/opinion/coronavirussuperspreaders.html.

Afelt, Aneta, Roger Frutos and Christian Devaux. 2018. "Bats, Coronaviruses, and Deforestation: Toward the Emergence of Novel Infectious Diseases?" Frontiers in Microbiology 9: 702.

Alon, Uri, Ron Milo, and Eran Yashiv. 2020. "10-4: How to Reopen the Economy by Exploiting the Coronavirus's Weak Spot.” The New York Times. May 11. Available: https://www.nytimes.com/2020/05/11/opinion/coronavirus-reopen.html.

Azmeh, Shamel. 2020. "The Perverse Economics of Ventilators," Project-Syndicate. April 16. Available: https://www.project-syndicate.org/commentary/ventilator-shortage-reflects-profitdriven-innovation-by-shamel-azmeh-2020-04.

Baldwin, Richard. 2020. "COVID-19 Testing for Testing Times: Fostering Economic Recovery and Preparing for the Second Wave." VoxEU. March 26. Available: https://voxeu.org/article/testing-testing-times.

Barro, Robert, Jose Ursua, and Joanna Weng. 2020. "The Coronavirus and the Great Influenza Pandemic: Lessons from the 'Spanish Flu' for the Coronavirus's Potential Effects on Mortality and Economic Activity.” NBER working paper 26866, March.

Berger, David, Kyle Herkenhoff, and Simon Mongey. 2020. “An SEIR Infectious Disease Model with Testing and Conditional Quarantine." Manuscript, Duke University, March.

Bethune, Zachary and Anton Korinek. 2020. "COVID-19 infection externalities: Pursuing herd immunity or containment?" COVID Economics, Vetted and Real-Time Papers 11, CEPR, April 29.

Bootsma, Martin C. J. and Neil M. Ferguson. 2007. "The Effect of Public Health Measures on the 1918 Influenza Pandemic in U.S. Cities.” PNAS, May 1, 104 (18): 7588-7593.

Available: https://doi.org/10.1073/pnas.0611071104.

Bossie, Andrew and J.W. Mason. 2020. "The Public Role in Economic Transformation: Lessons from World War II.” Roosevelt Institute working paper, March.

Bradley, Jane. 2020. "In Scramble for Coronavirus Supplies, Rich Countries Push Poor Aside." The New York Times. April 9. Online. Available:

https://www.nytimes.com/2020/04/09/world/coronavirus-equipment-rich-poor.html. 
Brotherhood, Luiz, Philipp Kircher, Cezar Santos and Michele Tertilt. 2020. "An Economic Model of the COVID-19 Epidemic: The importance of Testing and Age-specific Policies." Working paper.

Brunet, Gillian. 2020. "5 Lessons From World War II For the Coronavirus Response." Vox. April 10. Available: https:/www.vox.com/2020/4/10/21214980/coronavirus-economy-jobsppe.

Budish, Eric. 2020. ' $\mathrm{R}<1$ as an Economic Constraint: Can We 'Expand the Frontier' in the Fight Against Covid-19?” April 1. University of Chicago, working paper.

Cleevely, Matthew, Daniel Susskind, David Vines, Louis Vines, and Samuel Wills. "A workable strategy for Covid-19 testing: Stratified periodic testing rather than universal random testing." COVID Economics, Vetted and Real-Time Papers 8, CEPR, April 22.

CDC. 2019. "Historical Reference of Seasonal Influenza Vaccine Doses Distributed." Available: https://www.cdc.gov/flu/prevent/vaccine-supply-historical.htm.

Cerra, Valerie, Antonio Fatas, and Sweta Saxena. 2020. "Hysteresis and Business Cycles," CEPR Discussion Paper No. DP14531.

Cherif, Reda, Fuad Hasanov, and Min Zhu (eds). 2016. Breaking the Oil Spell: The Gulf Falcons' Path to Diversification. Washington, DC: IMF Press.

Cherif, Reda and Fuad Hasanov. 2019. "The Return of the Policy That Shall Not Be Named: Principles of Industrial Policy,” IMF Working Paper 19/074.

Corman, Victor, Tobias Bleicker, Sebastian Brunink, Christian Drosten, Olfert Landt, Marion Koopmans, and Maria Zambon. 2020. "Diagnostic Detection of 2019-nCoV by Real-Time RT-PCR.” January 17. World Health Organization. Online. Available: https://www.who.int/docs/default-source/coronaviruse/protocol-v2-1.pdf?sfvrsn=a9ef618c 2.

Correia, Sergio, Stephan Luck, and Emil Verner. 2020. "Pandemics Depress the Economy, Public Health Interventions Do Not: Evidence from the 1918 Flu." March. Working paper.

de Walque, Damien, Jed Friedman, Roberta Gatti, and Aaditya Mattoo. 2020. "How Two Tests Can Help Contain COVID-19 and Revive the Economy." Research and Policy Briefs. The World Bank. April 8.

Demirgüç-Kunt, Asli, Michael Lokshin, and Iván Torre. 2020. "The Sooner, the Better: The Early Economic Impact of Non-pharmaceutical Interventions During the COVID-19 Pandemic." May. World Bank working paper.

Denworth, Lydia. 2020. "How the COVID-19 Pandemic Could End." Scientific American. April 28. Online. Available: https://www.scientificamerican.com/article/how-the-covid-19pandemic-could-end/. 
Dingel, Jonathan and Brent Neiman. 2020. "How Many Jobs Can be Done at Home?" NBER Working Paper 26948.

Egilmezer, Ece, Gregory J. Walker, Padmavathy Bakthavathsalam, Joshua R. Peterson, J. Justin Gooding, William Rawlinson, and Sacha Stelzer-Braid. "Systematic Review of the Impact of Point-of-care Testing for Influenza on the Outcomes of Patients with Acute Respiratory Tract Infection." 2018. Reviews in Medical Virology 28(5). Available: https://doi.org/10.1002/rmv.1995.

Eichenbaum, Martin S., Sergio Rebelo, and Mathias Trabandt. 2020a. "The Macroeconomics of Testing and Quarantining." CEPR Working Paper 14688, May.

Eichenbaum, Martin S., Sergio Rebelo, and Mathias Trabandt. 2020b. "The Macroeconomics of Epidemics." NBER Working Paper 26882, April.

Fearnow, Benjamin. 2020. "Wuhan Tested Nearly 7 Million People in 12 Days to Prevent Second Coronavirus Wave, Health Officials Say." Newsweek. May 26. Available: https://www.newsweek.com/wuhan-tested-nearly-7-million-people-12-days-prevent-secondcoronavirus-wave-health-officials-say-1506537.

Ferretti, Luca, Chris Wymant, Michelle Kendall, Lele Zhao, Anel Nurtay, Lucie AbelerDörner, Michael Parker, David Bonsall, and Christophe Fraser. 2020. "Quantifying SARSCoV-2 transmission suggests epidemic control with digital contact tracing." Science 368 (6491), May 8. Available: https://science.sciencemag.org/content/368/6491/eabb6936.

Gollier, Christian and Olivier Gossner. 2020. "Group Testing Against Covid-19." COVID Economics, Vetted and Real-Time Papers 2, CEPR, April 8.

Hatchett, Richard J., Carter E. Mecher, and Marc Lipsitch. 2007. "Public Health Interventions and Epidemic Intensity During the 1918 Influenza Pandemic." PNAS, May 1, 104 (18): 75827587. Available: https://doi.org/10.1073/pnas.0610941104.

Hellewell, Joel, Sam Abbott, Amy Gimma, Nikos I. Bosse, Christopher I. Jarvis, Timothy W. Russell, James D. Munday, Adam J. Kucharski, W. John Edmunds, Sebastian Funk, Rosalind M Eggo, and Centre for the Mathematical Modelling of Infectious Diseases COVID-19 Working Group. 2020. "Feasibility of Controlling COVID-19 Outbreaks by Isolation of Cases and Contacts." The Lancet Global Health 8(4), April: E488-E496. Available: https://www.thelancet.com/journals/langlo/article/PIIS2214-109X(20)30074-7/fulltext.

Hill, Alison, Mike Levy, Sherrie Xie, Justin Sheen, Julianna Shinnick, Andre Gheorghe, and Chris Rehmann. 2020. "Modeling COVID-19 Spread vs. Healthcare Capacity." Online. Accessed April 15, 2020. Available: https://alhill.shinyapps.io/COVID19seir/?fbclid=IwAR2aXJT79M2AmZxMdy8jsiEuSC4i7ij U8Av6oB4dmlZIeJ2VQgL7Tt3QGxA. 
Hirschman, Albert. 1967. "The Principle of the Hiding Hand." National Affairs (Winter): 1023. Available: https://www.nationalaffairs.com/public interest/detail/the-principle-of-thehiding-hand.

Hone, Thomas. 1991. "Fighting on Our Own Ground: The War of Production, 1920-1942." Colloquium on Contemporary History 5, June 25. Available:

https://www.history.navy.mil/research/library/online-reading-room/title-listalphabetically/g/gearing-up-victory.html.

International Monetary Fund (IMF). 2020. Fiscal Monitor. April. Online. Available: https://www.imf.org/en/Publications/FM/Issues/2020/04/06/fiscal-monitor-april-2020.

Johnson, Steven. 2006. “The Ghost Map.” Riverhead Books. New York, New York.

Johns Hopkins University. 2020. "Coronavirus Resource Center.” The Center for Systems Science and Engineering. Available: https://coronavirus.jhu.edu/map.html.

Jones, James. 2007. "Notes on $R_{0}$." Stanford University. May 1. Online. Accessed: April 25, 2020. Available: https://web.stanford.edu/ jhj1/teachingdocs/Jones-on-R0.pdf.

Johnson \& Johnson. 2019. "Innovation \& Imagination: 5 Questions for Johnson \& Johnson's Chief Global Supply Chain Officer." September 16. Available:

https://www.jnj.com/innovation/5-questions-for-johnson-johnsons-chief-global-supply-chainofficer.

Kai, De, Guy-Philippe Goldstein, Alexey Morgunov, Vishal Nangalia, and Anna Rotkirch. 2020. "Universal Masking is Urgent in the COVID-19 Pandemic: SEIR and Agent Based Models, Empirical Validation, Policy Recommendations.” Working paper. Available: https://arxiv.org/pdf/2004.13553.pdf.

Klein, Maury. 2013. A Call to Arms: Mobilizing America for World War II. New York: Bloomsbury Press.

Kofler, Natalie and Françoise Baylis. "Ten Reasons Why Immunity Passports Are a Bad Idea.” Nature. May 21. Available: https://www.nature.com/articles/d41586-020-01451-0.

Korber,B., W.M. Fischer, S. Gnanakaran, H. Yoon, J. Theiler, W. Abfalterer, B. Foley, E.E. G iorgi, T. Bhattacharya, M.D. Parker, D.G. Partridge, C.M. Evans, T.M. Freeman, T.I. de Silva, C.C. LaBranche, and D.C. Montefiori. 2020. "Spike Mutation Pipeline Reveals the Emergence of a More Transmissible Form of SARS-CoV-2." BioRxiv. May 5. Available: https://www.biorxiv.org/content/10.1101/2020.04.29.069054v2.

Kotlikoff, Laurence. 2020. "Group Testing Is Our Surefire Secret Weapon Against Coronavirus.” Forbes, March 29. Available: 
https://www.forbes.com/sites/kotlikoff/2020/03/29/group-testing-is-our-secret-weaponagainst-coronavirus/\#3c95ab6f36a6.

Krugman, Paul. 2020. "On the Economics of Not Dying." The New York Times. May 28. Available: https://www.nytimes.com/2020/05/28/opinion/coronavirus-economy-death.html.

Kucharski, Adam J., Petra Klepac, Andrew J. K. Conlan, Stephen M. Kissler, Maria Tang, Hannah Fry, Julia R. Gog, and W. John Edmunds. 2020. "Effectiveness of Isolation, Testing, Contact Tracing and Physical Distancing on Reducing Transmission of SARS-CoV-2 in Different Settings." MedRxiv. April 29. Available: https://www.medrxiv.org/content/10.1101/2020.04.23.20077024v1.

Leung, Kathy, Joseph T Wu, Di Liu, and Gabriel M Leung. 2020. "First-Wave COVID-19 Transmissibility and Severity in China Outside Hubei After Control Measures, and SecondWave Scenario Planning: A Modelling Impact Assessment." The Lancet. Online. April 8. Available: https://doi.org/10.1016/S0140-6736(20)30746-7.

Lipton, Eric and Jennifer Steinhauer. 2020. "The Untold Story of the Birth of Social Distancing." The New York Times. April 22. Online. Available: https://www.nytimes.com/2020/04/22/us/politics/social-distancing-coronavirus.html.

Lunden, Ingrid. 2020. "Gartner: 2020 device shipments to grow $0.9 \%$ to $2.16 \mathrm{~B}$ thanks to $5 \mathrm{G}$, before 2 further years of decline." TechCrunch. January 21. Available: https://techcrunch.com/2020/01/21/gartner-forecast-2020-to-see-0-9-bump-in-global-deviceshipments-thanks-to-5g-then-2-more-years-of-decline/.

Ma, Chang, John Rogers, and Sili Zhou. 2020. "Global Economic and Financial Effects of Modern Pandemics and Epidemics," Working paper.

Maier, Charles and Ian Kumekawa. 2020. "Responding to COVID-19: Think through the Analogy of War.” Edmond J. Safra Center for Ethics, Harvard University, April 21.

Mallapaty, Smriti. 2020. "How Sewage Could Reveal True Scale of Coronavirus Outbreak." Nature 580, April 3: 176-177. Available: https://www.nature.com/articles/d41586-020-00973$\underline{x}$.

Maxmen, Amy. 2020. "Scientists baffled by decision to stop a pioneering coronavirus testing project.” Nature. May 22. Available: https://www.nature.com/articles/d41586-020-01543-x.

Miller, Joe and Hannah Kuchler. 2020. "Drugmakers Race to Scale Up Vaccine Capacity." Financial Times. April 27. Available: https://www.ft.com/content/87d1170a-78bc-11ea-bd25$\underline{7 \mathrm{fd} 923850377 .}$.

Moore, Kristine A., Marc Lipsitch, John M. Barry, and Michael T. Osterholm. 2020. "Part 1: The Future of the COVID-19 Pandemic: Lessons Learned from Pandemic Influenza." COVID-19: The CIDRAP Viewpoint. CIDRAP, University of Minnesota, April 30. 
Available: https://www.cidrap.umn.edu/sites/default/files/public/downloads/cidrap-covid19viewpoint-part1.pdf.

Okonjo-Iweala, Ngozi. 2020. “Ebola Lessons for Fighting COVID-19.” Project Syndicate. April 1. Available: https://www.project-syndicate.org/commentary/africa-ebola-outbreaklessons-for-covid19-by-ngozi-okonjo-iweala-2020-04.

Oliu-Barton, Miquel, Bary Pradelski, and Luc Attia. 2020. "Exit Strategy: From SelfConfinement to Green Zones." Esade - Center for Economic Policy \& Political Economy, Policy Insight No. 6, April.

Peak, Corey M., Rebecca Kahn, Yonatan H. Grad, Lauren M. Childs, Ruoran Li, Marc Lipsitch, Caroline O. Buckee. 2020. "Individual Quarantine versus Active Monitoring of Contacts for the Mitigation of COVID-19: A Modelling Study." The Lancet Infectious Diseases. May 20. Available: https://www.thelancet.com/journals/laninf/article/PIIS14733099(20)30361-3/fulltext\#\%20.

PBS. 2020. "War Production." Available:

https://www.pbs.org/thewar/at_home_war_production.htm.

Phillips, Howard. 2017. "Influenza Pandemic (Africa)" in 1914-1918-online. International Encyclopedia of the First World War, ed. by Ute Daniel, Peter Gatrell, Oliver Janz, Heather Jones, Jennifer Keene, Alan Kramer, and Bill Nasson, issued by Freie Universität Berlin, Berlin 2014-10-08. Available: https://encyclopedia.1914-1918online.net/article/influenza pandemic africa/2014-10-08.

Piguillem, Facundo and Liyan Shi. 2020. "The Optimal COVID-19 Quarantine and Testing Policies.” Working paper No. 2004. Einaudi Institute for Economics and Finance.

Pueyo, Tomas. 2020. "Coronavirus: The Basic Dance Steps Everybody Can Follow." Medium. April 23. Available: https://medium.com/@tomaspueyo/coronavirus-the-basicdance-steps-everybody-can-follow-b3d216daa343.

Romer, Paul. 2020a. "How to Restart the Economy after COVID-19." Webinar. Bendheim Center for Finance at Princeton University. Accessed: April 15, 2020. Available: https://bcf.princeton.edu/event-directory/covid19 04/.

Romer, Paul. 2020b. "Road to Responsibly Reopen America.” Manuscript, April 23. Available: https://paulromer.net/roadmap-to-reopen-america/.

Rose, Joel. 2020. "Coronavirus Testing Machines Are Latest Bottleneck In Troubled Supply Chain.” NPR. May 28. Available: https://www.npr.org/2020/05/28/863558750/coronavirustesting-machines-are-latest-bottleneck-in-troubled-supply-chain.

Rosenblatt, Stuart. 2018a. "Part One: FDR and Jesse Jones Prepare the Way." May 18. Available: https://americansystemnow.com/urgent-lessons-of-the-wwii-mobilization/. 
Rosenblatt, Stuart. 2018b. "Producing a Machine Tool Revolution.” June 19. Available: https://americansystemnow.com/producing-a-machine-tool-revolution/.

Rosenblatt, Stuart. 2018c. “Creating New Industries from Scratch.” July 10. Available: https://americansystemnow.com/creating-new-industries-from-scratch/.

Rosenblatt, Stuart. 2018d. "The Quintessential Mobilization Economy." July 21. Available: https://americansystemnow.com/the-quintessential-mobilization-economy/.

Roser, Max, Hannah Ritchie, Esteban Ortiz-Ospina and Joe Hasell. 2020. "Coronavirus Pandemic (COVID-19)." Our World in Data. Available:

https://ourworldindata.org/coronavirus.

Salami, Joseph A., Haider Warraich, Javier Valero-Elizondo, Erica S. Spatz, Nihar

R. Desai, Jamal S. Rana, Salim S. Virani, Ron Blankstein, Amit Khera, Michael

J. Blaha, Roger S. Blumenthal, Donald Lloyd-Jones, Khurram Nasir. 2017. "National Trends in Statin Use and Expenditures in the US Adult Population From 2002 to 2013: Insights From the Medical Expenditure Panel Survey." JAMA Cardiology 2(1): 56-65. Available:

doi:10.1001/jamacardio.2016.4700.

Sanderson, Grant. 2020. "Simulating an Epidemic.” Online. Accessed: April 15, 2020.

Available: https://www.youtube.com/watch? $\mathrm{v}=\mathrm{gxAaO} 2 \mathrm{rsdIs}$.

Shental, Noam, Shlomia Levy, Vered Wuvshet, Shosh Skorniakov, Yonat Shemer-Avni, Angel Porgador, and Tomer Hertz. "Efficient high throughput SARS-CoV-2 testing to detect asymptomatic carriers." Working paper. Available:

https://www.medrxiv.org/content/10.1101/2020.04.14.20064618v1.full.pdf.

Siddarth, Divya and E. Glen Weyl. 2020. "Why We Must Test Millions a Day." Edmond J. Safra Center for Ethics, Harvard University, April 8.

Statista. 2020. "Soft Drinks.” Available: https://www.statista.com/outlook/20020000/100/softdrinks/worldwide\#market-volume.

Steven Sanche, Yen Ting Lin, Chonggang Xu, Ethan Romero-Severson, Nick Hengartner, and Ruian Ke. 2020. "High Contagiousness and Rapid Spread of Severe Acute Respiratory Syndrome Coronavirus 2." Emerging Infectious Diseases 26 (7), July. Available: https://wwwnc.cdc.gov/eid/article/26/7/20-0282 article?deliveryName=USCDC 333DM25287.

Stiglitz, Joseph E., Arjun Jayadev, and Achal Prabhala. "Patents vs. the Pandemic." Project Syndicate. April 23. Available: https://www.project-syndicate.org/commentary/covid19drugs-and-vaccine-demand-patent-reform-by-joseph-e-stiglitz-et-al-2020-04.

Storbeck, Olaf. 2020. "German Manufacturer Uses Weekly Covid-19 Tests to Stay Open." Financial Times. June 4. Available: https://www.ft.com/content/4f7b1fc5-ebf3-4cc7-afaf$\underline{80 f 4 c a f c f c b 9}$. 
Strochlic, Nina and Riley Champine. 2020. "How Some Cities 'Flattened the Curve' During the 1918 Flu Pandemic.” National Geographic. March 27. Online. Available:

https://www.nationalgeographic.com/history/2020/03/how-cities-flattened-curve-1918spanish-flu-pandemic-coronavirus/.

Tassava, Christopher. 2003. "Launching a Thousand Ships: Entrepreneurs, War Workers, and the State in American Shipbuilding, 1940-1945." PhD Dissertation. Northwestern University. June. Available:

http://citeseerx.ist.psu.edu/viewdoc/download?doi=10.1.1.129.5520\&rep=rep1\&type=pdf.

The Economist. 2020a. "The Quest for a Vaccine Could Restore Faith in Big Pharma." June 6. Online. Available: https://www.economist.com/business/2020/06/06/the-quest-for-a-vaccinecould-restore-faith-in-big-pharma.

The Economist. 2020b. "Can the World Find a Good COVID-19 Vaccine Quickly Enough?" April 16. Online. Available: https://www.economist.com/briefing/2020/04/16/can-the-worldfind-a-good-covid-19-vaccine-quickly-enough.

The IQVIA Institute. 2019. "The Global Use of Medicine in 2019 and Outlook to 2023: Forecasts and Areas to Watch.” Report. January 29. Available:

https:/www.iqvia.com/en/insights/the-iqvia-institute/reports/the-global-use-of-medicine-in2019-and-outlook-to-2023.

This is Capitalism. 2020. "Capitalism in WWII: The Arsenal of Democracy." Available: https://www.thisiscapitalism.com/capitalism-in-wwii-the-arsenal-of-democracy/.

Trainor, Tim. 2019. "How Ford's Willow Run Assembly Plant Helped Win World War II." Assembly. January 3. Available: https://www.assemblymag.com/articles/94614-how-fordswillow-run-assembly-plant-helped-win-world-war-ii.

Verity, Robert, Lucy C. Okell, Ilaria Dorigatti, Peter Winskill, Charles Whittaker, Natsuko Imai, Gina Cuomo-Dannenburg, et al. 2020. "Estimates of the Severity of COVID-19 Disease." medRxiv, March.

Waxman, Olivia. 2020. "The U.S. Government Has Mobilized Private Companies to Face Crises Before. Here's What to Know." Time. March 24. Available:

https://ime.com/5808389/coronavirus-mobilization-war-industry-history/.

Wilson, Mark. 2020. "The 5 WWII Lessons that Could Help the Government Fight Coronavirus." Politico. March 19. Available:

https://www.politico.com/news/magazine/2020/03/19/coronavirus-defense-production-worldwar-two-lessons-135814.

Yglesias, Matthew. 2020. "Experts' 7 Best Ideas on How to Beat Covid-19 and Save the Economy." Vox. May 13. Available: https://www.vox.com/2020/5/13/21248157/testingquarantine-masks-stimulus. 
Zeitlin, Matthew. 2020. "There's One Way We Really Are 'at War' With the Coronavirus." Slate. March 18. Available: https://slate.com/business/2020/03/coronavirus-war-world-warii.html.

Zingales, Luigi. 2020. "Why Mass Testing Is Crucial: the US Should Study the Veneto Model to Fight Covid-19." The Blog of the Stigler Center at the University of Chicago Booth School of Business. March 17. Online. Available: https://promarket.org/why-mass-testing-is-crucialthe-us-should-study-the-veneto-model-to-fight-covid-19/. 